SANDIA REPORT

SAND96-0200 • UC-703

Unlimited Release

Printed January 1996

Ater

MAR 041000

OSTI

\title{
GAGE COOKBOOK: Tools and Techniques to Measure Stresses and Motions on Explosive Experiments
}

Carl W. Smith

\section{Prepared by}

Sandia National Laboratories

Albuquerque, New Mexico 87185 and Livermore, California 94550

for the United States Department of Energy

under Contract DE-AC04-94AL85000

Approved for public release; distribution is unlimited.

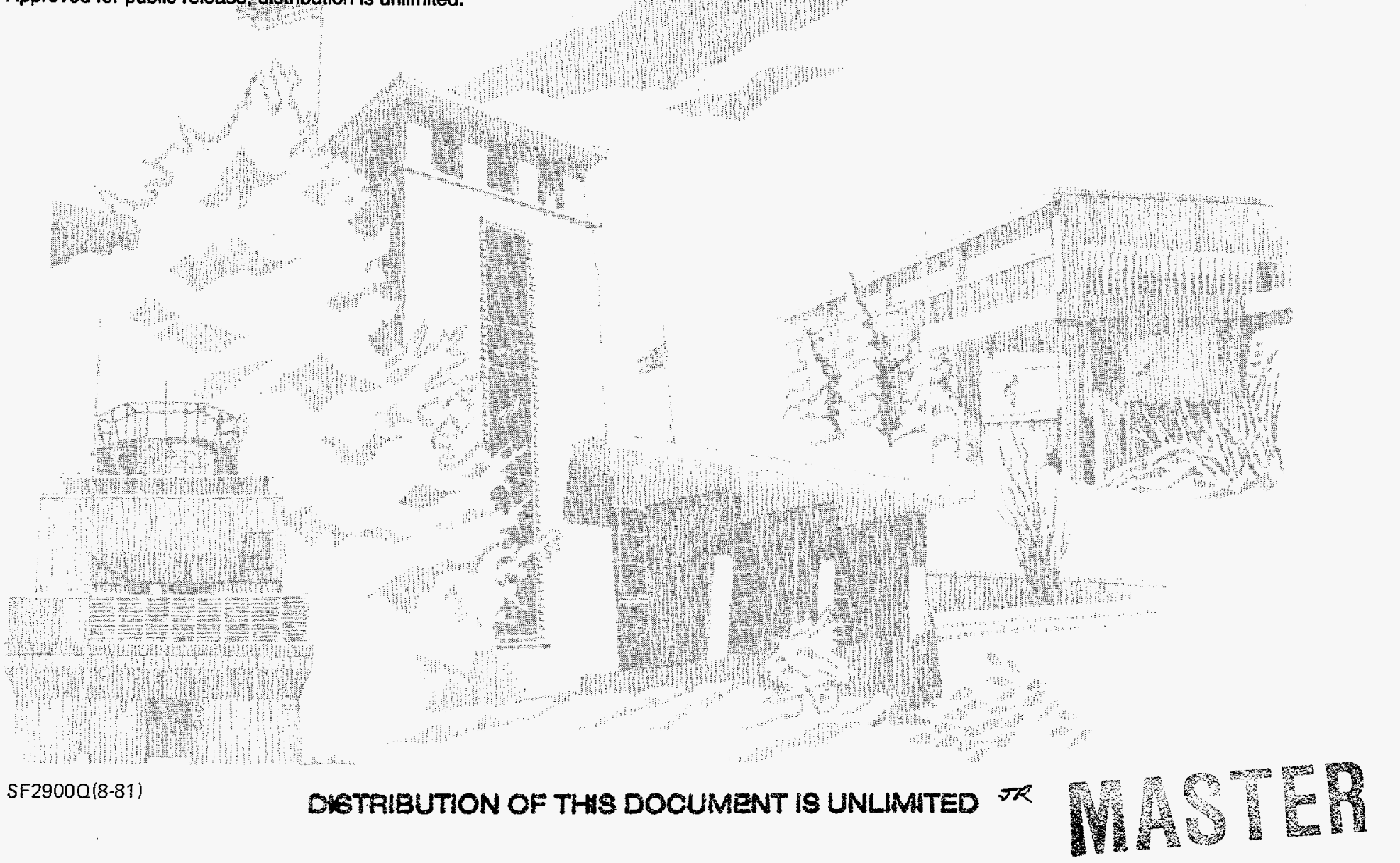


Issued by Sandia National Laboratories, operated for the United States Department of Energy by Sandia Corporation.

NOTICE: This report was prepared as an account of work sponsored by an agency of the United States Government. Neither the United States Government nor any agency thereof, nor any of their employees, nor any of their contractors, subcontractors, or their employees, makes any warranty, express or implied, or assumes any legal liability or responsibility for the accuracy, completeness, or usefulness of any information, apparatus, product, or process disclosed, or represents that its use would not infringe privately owned rights. Reference herein to any specific commercial product, process, or service by trade name, trademark, manufacturer, or otherwise, does not necessarily constitute or imply its endorsement, recommendation, or favoring by the United States Government, any agency thereof or any of their contractors or subcontractors. The views and opinions expressed herein do not necessarily state or reflect those of the United States Government, any agency thereof or any of their contractors.

Printed in the United States of America. This report has been reproduced directly from the best available copy.

Available to DOE and DOE contractors from

Office of Scientific and Technical Information

PO Box 62

Oak Ridge, TN 37831

Prices available from (615) 576-8401, FTS 626-8401

Available to the public from

National Technical Information Service

US Department of Commerce

5285 Port Royal Rd

Springfield, VA 22161

NTIS price codes

Printed copy: A03

Microfiche copy: A01 


\section{DISCLAIMIER}

Portions of this document may be illegible in electronic image products. Images are produced from the best available original document. 
SAND 96-0200

Distribution

Unlimited Release

Category UC-703

Printed January 1996

\title{
GAGE COOKBOOK: Tools and Techniques to Measure Stresses and Motions on Explosive Experiments
}

\author{
Carl W. Smith \\ Applied Technology Department \\ Sandia National Laboratories \\ Albuquerque, NM 87185
}

\begin{abstract}
Tools and techniques developed to measure stresses and motiones on underground nuclear and high explosive tests in the tuff geologies at the Nevada Test Site are described in this document. The thrust of the measurements was to understand containment phenomenology. We concentrate on the fluid-coupled ytterbium gage; it was fielded to measure dynamic stress in the 0.2 to 20 kilobar range and the subsequent, low amplitude residual stress. Also described are accelerometer packages; their traces were integrated to obtain particle motion.

Various cable survival techniques were investigated with field measurements for we wished to extend the measurements to late-time.

Field measurements were also made to address the gage inclusion problem. Work to date suggests that the problem is a minimum when the stress level is above the yield strength of the host rock and grout. Below the yield level stress amplitudes in the grouted hole can range from 60 to $200 \%$ of the stress in the host rock.
\end{abstract}




\section{Acknowledgment}

Funding for the writing of this document was provided by Field Command/Defense Nuclear Agency under Sandia proposal number 93930727 . The contract monitor was Byron Ristvet who not only suggested the topic but also reviewed the draft. I am also indebted to Dan Patch and Ken Glibert for technical and editorial reviews of the document. 


\section{Table of Contents}

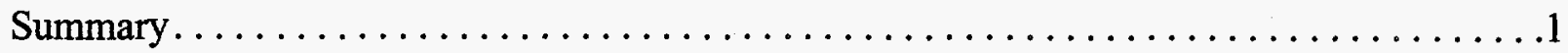

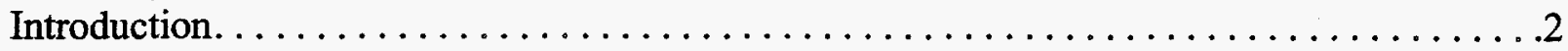

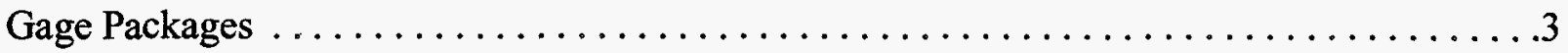

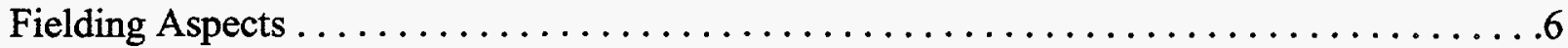

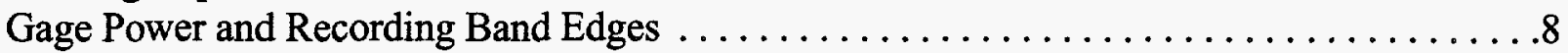

Data Reduction ............................................. 10

Gage and Cable Survival. .......................................

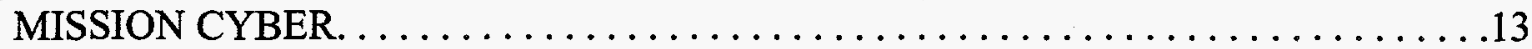

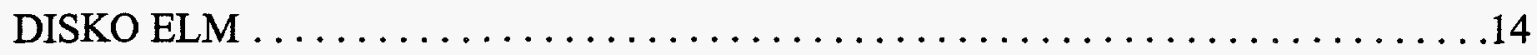

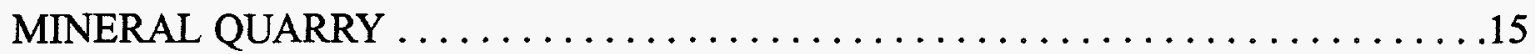

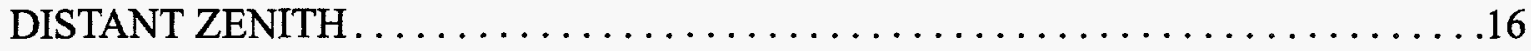

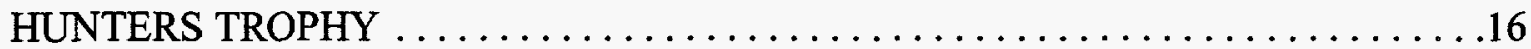

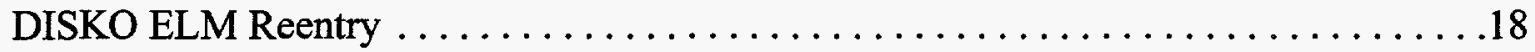

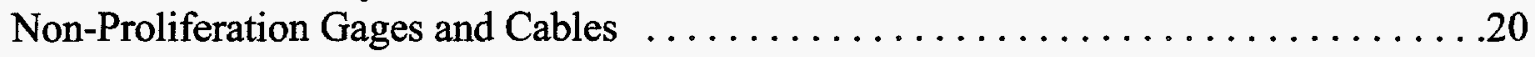

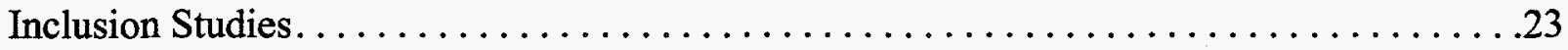

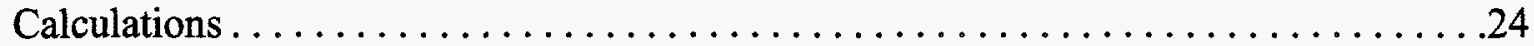

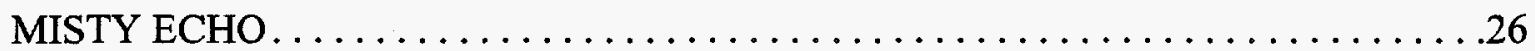

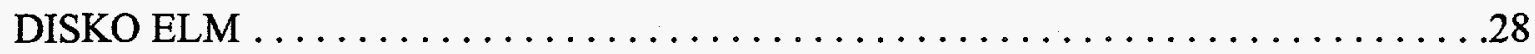

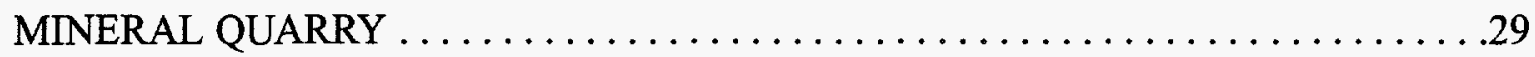

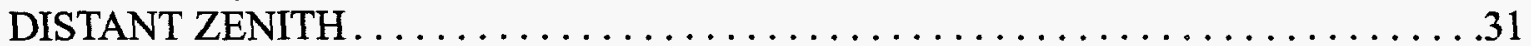

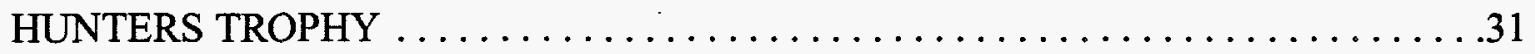

High Explosive Tests . . . . . . . . . . . . . . . . . . . . . . . . . . . . . 32

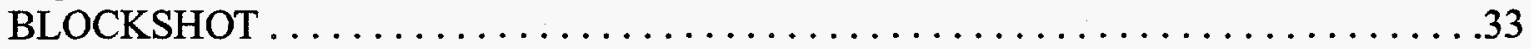

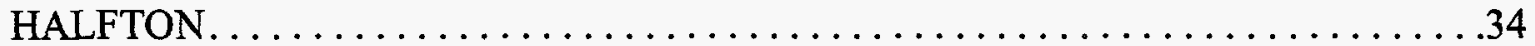

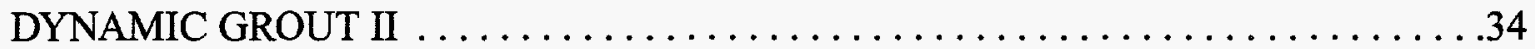

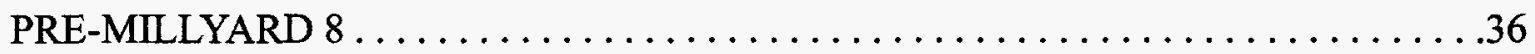

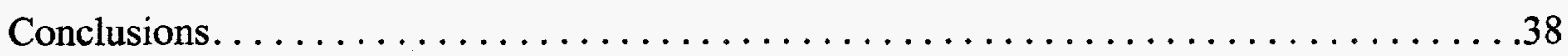

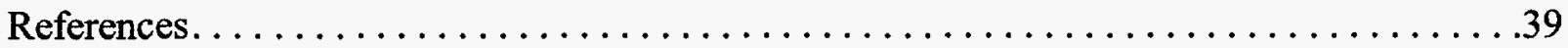

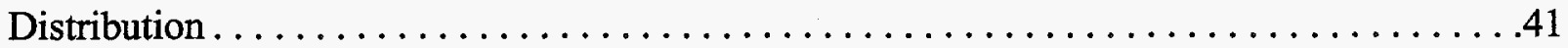




\section{Figures}

1 Waveforms from: Fluid-Coupled Grids (Left) and Solid-Coupled

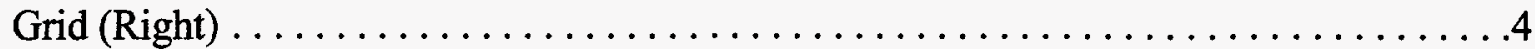

2 Waveforms from Radial Hole Installation - MISTY RAIN . . . . . . . . . . . . . . 7

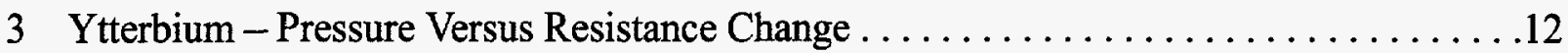

4 SCEMS Reentry - Vertical Section ................................. 19

5 Manganin Gage Waveform - Middle Gust, Event $1 \ldots \ldots \ldots \ldots \ldots \ldots \ldots \ldots \ldots \ldots \ldots \ldots \ldots$

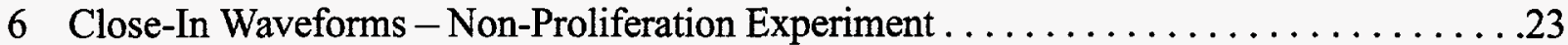

7 Radially Installed Epoxy Package and Static Stress Distribution . . . . . . . . . . . . . 25

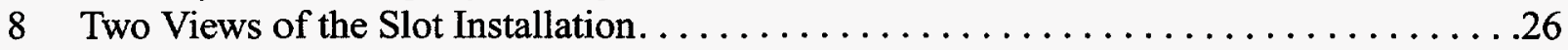

9 Waveforms from Paddle Gages - MISTY ECHO ...................... 28

10 Waveforms from Slot Installations (Solid Traces) and Hole Installations (Dashed Traces) - DISKO ELM . . . . . . . . . . . . . . . . . . 29

11 Waveforms from a Radially Installed Gage (Solid Trace) and Transversely Installed Gages (Other Traces) - MINERAL QUARRY ...................30

12 Waveforms from Adjacent Gages - DISTANT ZENITH $\ldots \ldots \ldots \ldots \ldots \ldots \ldots \ldots . . . \ldots \ldots$

13 Waveforms from IH4 and IH5 Gages - HUNTERS TROPHY $\ldots \ldots \ldots \ldots \ldots \ldots . . \ldots \ldots$

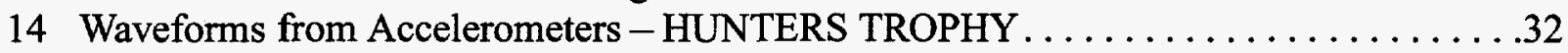

15 Waveforms from Radially Installed Gages - HUNTERS TROPHY . . . . . . . . . 33

16 Waveforms from Paddle Gages - HALFTON........................... 35

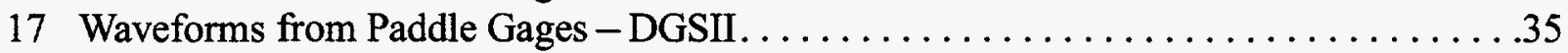

18 Waveforms from Two Cylinder Gages and Two Paddle

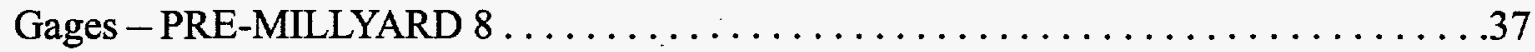




\section{Summary}

With the cessation of underground nuclear testing, field experimenters are attempting to document the measurement tools and techniques that have been developed to date and to describe the current state of the art. Two reasons motivate this work: limited testing could be renewed, and the tools and techniques are applicable to high-explosive, and other dynamic, experiments.

In this document we describe the development and fielding of instruments whose main thrust was to assess containment phenomenology. We concentrate on a gage that measures stress in the 0.2 to 20 kilobar regime and in a spherically divergent, flow field. The sensor is the piezoresistive material ytterbium. The host material was the weak, volcanic tuffs typical of the tunnels at the Nevada Test Site. Also described are commercially available acceleration sensors that were packaged and fielded to obtain motion measurements in the 1 to $40 \mathrm{~meter} / \mathrm{second}$ regime.

Cable survival of the displacements associated with dynamic loading and fault motions were investigated for we wished to obtain the long term residual stress. We found that modestly hardened cables - hydraulic hose and wire rope - do not survive differential fault motions at the nominal one kilobar stress level.

When gages are inserted in drill holes and coupled to the host rock with a cement-like grout, the stress in the grouted hole may differ from that in the host. We studied, and made measurements on, this so-called gage inclusion effect. Our incomplete work suggests that these effects are minimized when the stress levels are above the mechanical yield of the host and grout materials. Below yield levels, measured stresses in the inclusion can range from 60 to $200 \%$ of the stress in the host rock. 


\section{GAGE COOKBOOK: Tools and Techniques to Measure Stresses and Motions on Explosive Experiments}

\section{Introduction}

In this report we document the technology developed to measure dynamic stresses and motions in saturated tuff rocks. The stress range is 0.2 to 10 kilobars; the particle velocity range is 1 to 40 meters/second. Explosive sources were the Defense Nuclear Agency (DNA) nuclear events, and the Sandia high-explosive events, conducted at the Nevada Test Site. The measurements were primarily related to containment of underground nuclear events, that is, the response of the host rock to the explosion and the subsequent containment of the radioactive debris within the explosion produced cavity.

The original measurement requests were for indications of stress and motion versus time to compare with calculations that modeled the process. Gage precision (repeatability or closeness to a mean) and gage accuracy (lack of a systematic bias) were not major issues at that time ${ }^{1}$ for these reasons: (1) the equation of state of the rock, used in the calculations, was not well known; (2) geologic inhomogeneities were expected to strongly influence gage measurements; and (3) funding and recording channels were limited as these were not priority measurements. As containment requirements became more stringent and material models were improved, gage response studies were initiated. Also, the value of calculational modeling of proposed events became apparent. Briefly, the gage response problem is the following: given the measured waveform, find the portion that represents the free-field stress or motion, and the portion that is contributed by the gage package, the drill hole, the coupling grout, the electrical cable, and the recording electronics. Some of these issue have been solved; others have been bounded. Statistics on gage repeatability need to be established. Measurements of the same quantity with different sensors need to be made to probe the issue of systematic bias.

In the following sections we discuss the "nuts and bolts" aspects: gage packages, fielding aspects, gage power, recording, and data reduction. Subsequent sections treat the less developed aspects of gage and cable survival studies and inclusion effects.

Although we often mention the work of others, this document is not meant to be a survey of the field. We wish to describe our tools, techniques, and experience in this field to aid a future experimenter who may be required to make these types of measurements on a nuclear event. The techniques can also be used on high-explosive events that range from verification type experiments to mining applications.

1. While the nuclear measurements community was worrying about losing their gage traces to an EMP burst, or an erroneous trigger, Jack Trulio of ATI was discussing and writing about these accuracy and precision issues. A succinct account of these in given in his 1991 NWET Conference paper (Truilio, 1991). 


\section{Gage Packages}

The ytterbium fluid coupled (YBFC) paddle has been the principal stress gage package that we have fielded in the past ten years. The genesis of the paddle configuration was the need for a package to hold a new stress sensor, ytterbium, for measurements on the Area 16 (NTS) events: DIAMOND MINE, DIAMOND DUST, and MINE DUST. The gage work was performed by Stanford Research Institute under DNA sponsorship. Ytterbium grids of $6 \mathrm{ohm}$ resistance were photo etched from high purity 2 mil thick $(0.05 \mathrm{~mm})$ foil and sandwiched between pieces of fiberglass-epoxy board. Typically, $1 / 16$ inch thick $(1.6 \mathrm{~mm})$ board was used. The paddles were $\sim 3$ inches $(7.6 \mathrm{~cm})$ wide by 12 inches $(30 \mathrm{~cm})$ long and were tapered at one end where aluminum tubes were attached. The latter contained the electrical cable and served as a handling fixture. The paddle was designed to be loaded perpendicular to its face by the radial component of stress. Being "thin" in the direction of wave propagation and of a mechanical impedance (wave speed times density) similar to the host rock and grout, it was expected to rapidly come into equilibrium with the stress in the host.

For the calibration of ytterbium we used the work of Ginsberg (1973). This gas gun work showed that the resistance change of ytterbium is a nonlinear function of applied stress. Specific formulas are given in the data reduction section. The unloading from the peak level is linear, but the zero stress, resistance value is offset from the initial gage resistance, i.e., the material shows a hysteresis effect. The source of this effect is the plastic strain induced in the ytterbium when it is deformed in uniaxial strain. Waveforms from these paddles in 100 pound $(46 \mathrm{~kg})$ high-explosive experiments in wet sand showed an additional, spurious effect (Grady et al. 1974). In the unloading phase, the resistance change decreased below the initial value and then returned to positive values. We suspected that lateral strain, due to spherical divergence, was stretching the grid, that is, a strain gage effect. Thus, in the unloading phase, the resistance change consists of three parts: 1) the desired change associated with radial stress, 2) the ytterbium hysteresis, and 3) the change caused by lateral strain. Ginsberg (1973) explored the phenomenology of the lateral strain effect in the laboratory by bonding a ytterbium grid to a standard "dog bone" specimen and loading it in a tensile testing machine. Most metals loaded this way show a positive resistance change versus strain; this is the standard strain gage effect and shows a resistance change versus strain coefficient of two. Ytterbium shows a negative coefficient until the material yields. Then it shows the usual positive coefficient. (Being a rare earth element, ytterbium has an unusual electron configuration.) This negative strain coefficient was the source of the negative resistance in the unloading phase on the high-explosive tests mentioned earlier.

In the early 1970 s workers in the nuclear containment community postulated that the residual stress effect that is observed in metals may also occur in rock. The effect consists of a long term stress in the rock about an explosively formed cavity. Nominally, it is this postulated effect that prevents cavity pressure from driving a hydraulic fracture through the cavity wall and releasing the pressure and radioactive debris. We wished to measure this effect on nuclear events and investigate its phenomenology with high-explosive experiments. Because of its sensitivity in the low kilobar range, ytterbium was the logical sensor to use for these studies. The disadvantage was that the amplitude of residual stress was about the same as the ytterbium hysteresis and lateral strain effects. Further, they occur in a similar timeframe. We noted in the work of Lilley and Stephens 
(1971) that ytterbium shows no hysteresis effect when loaded hydrostatically. We proposed to utilize this property by encapsulating a ytterbium grid in a fluid cell. By using a high aspect ratio cell (thin in the direction of wave propagation), we expected the pressure in the cell to rapidly come to equilibrium with the applied stress. Calculational modeling of this geometry suggests that this indeed occurs; that is, the pressure in the cell is a close analog of the stress. The second aspect of the fluid cell consists of "holding" the ytterbium grid on one side only. Then, as spherical divergence stretches the cell which is encapsulated in the paddle, the lateral strain is not coupled to the ytterbium grid. Any long term amplitude after the passage of the dynamic wave should be the desired residual stress with no "contamination" from ytterbium hysteresis nor lateral strain. Typically, the fluid cell is held between two thin fiberglass-epoxy boards which form the paddle; open spaces are filled with epoxy. The usual thickness of the paddle is 10 millimeters; the transit time through the composite is about 4.4 microseconds.

We fielded a long paddle on a 64 pound $(29 \mathrm{~kg}$ ) high-explosive experiment in zeolitized tuff. Three fluid cells with ytterbium grids were incorporated in the paddle; the coupling fluids were silicon fluid, glycerin, and mercury. Additionally, there was a "bare", or solid-coupled, grid in a sandwich of fiberglass board. Figure 1 from Smith and Burnside (1982) shows the similar waveforms from the three grids in the fluid cells and the waveform from the bare grid. We believe that the long term amplitude, shown by the grids in the fluid cells, is the residual stress. For the
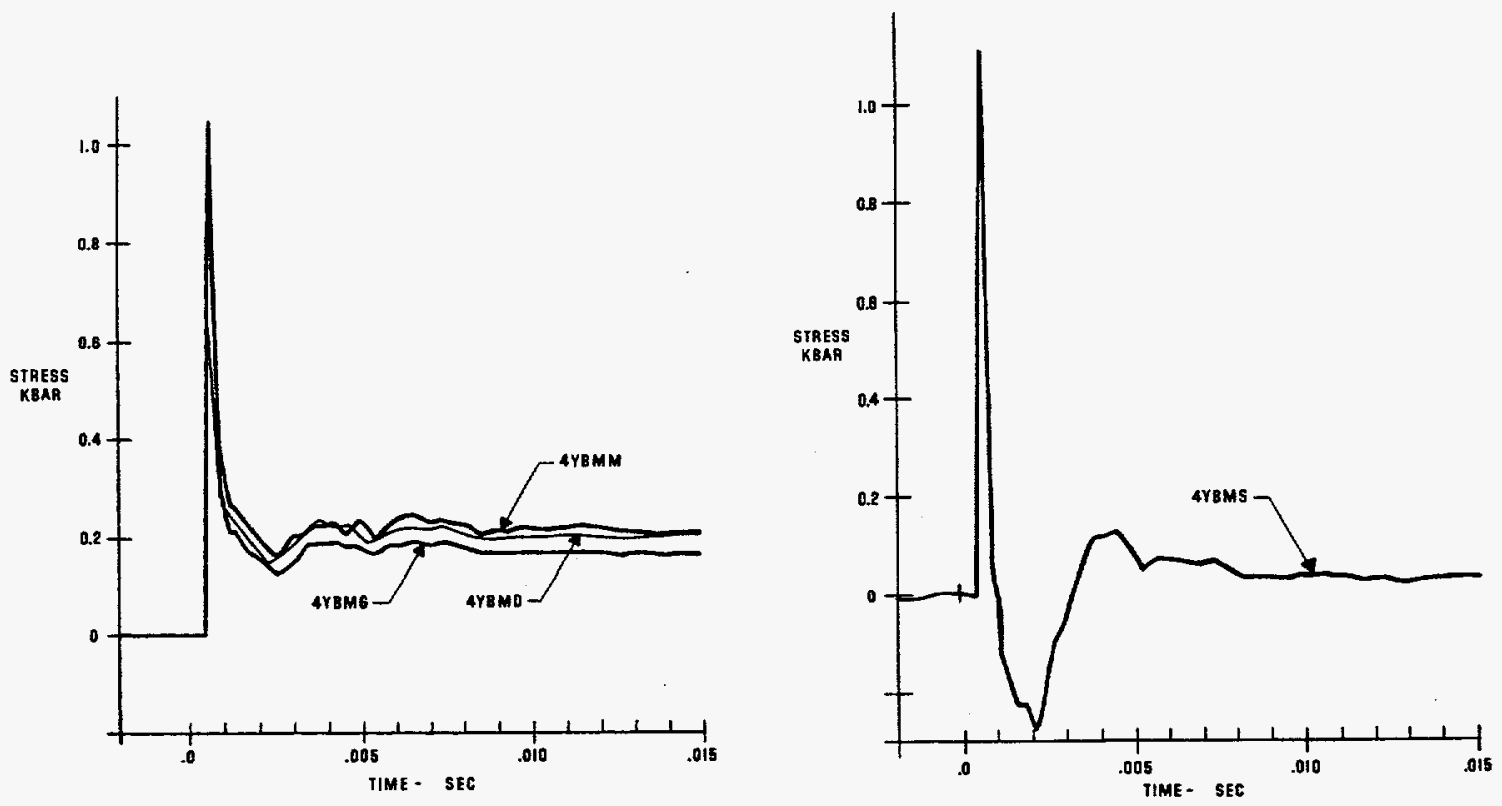

Figure 1. Waveforms from: Fluid-Coupled Grids (Left) and Solid-Coupled Grid (Right)

bare grid the amplitude after the peak is a combination of: residual stress, ytterbium hysteresis, and lateral strain effects. We suspect that the negative amplitude in the 0.001 to 0.005 second timeframe is caused by the lateral strain "exercising" the negative, strain gage response of the ytterbium. The resistance changes shown by the four peaks are within $\pm 10 \%$ of the mean. Further, among the three fluid cells, the peaks increased with increasing bulk modulus of the coupling fluid. At one kilobar the moduli of these three fluids are: 250 kilobars for mercury, 50 kilobars for 
glycerin, and 24 kilobars for silicon fluid. Subsequently we have used glycerin in the cells. Over zero to four kilobars its stiffness is a reasonable match to that of the tuff. Regarding construction, it is obvious that one needs to electrically isolate the ytterbium grid and its electrical leads in the mercury cell. One also needs to isolate the ytterbium from the glycerin as the latter is very hygroscopic and the water, absorbed by the glycerin, attacks the ytterbium.

With the measurements on the 64 pound $(29 \mathrm{~kg})$ experiment, and on a 1000 pound $(453 \mathrm{~kg})$ experiment, we believed that the YBFC paddle was a useful tool to measure the dynamic and long term stresses and have subsequently used it on nuclear and high-explosive events.

A variation on the paddle configuration consisted of encapsulating a circular shaped fluid cell in a cylinder of epoxy for use in a radially oriented drill hole. This configuration is discussed in the section on inclusion studies.

Now we turn to a brief description of the accelerometer package. Earlier Sandia experimenters, Luke Vortman and William Perret, had fielded accelerometer packages on large nuclear and highexplosive events. These were six to eight inch $(15$ to $20 \mathrm{~cm})$ diameter aluminum packages with sufficient void space that the packages were density matched to the host material. We were inter-. ested in packages that would fit in four to six inch $(10$ to $15 \mathrm{~cm})$ diameter holes on penetrator experiments and on DNA events at NTS. The dimensions of the accelerometer itself, usually an Endevco piezoresistive unit, are 4 by 6 by 10 millimeters; the unit utilizes very small diameter electrical leads. Thus, one needs a package to handle, install, and cable the tiny unit and to smooth any response from local disturbances such as that caused by a hard pebble. We chose an aluminum box of dimensions of 3 by 4.5 by 8 centimeters with 6 millimeter thick walls. The transducer is attached to the inside base of this box, electrical connections made to "blue quad" cable, and the box is "backfilled" with a low density rubber compound. ${ }^{1}$ The fill keeps the electrical leads from moving during dynamic motion and prevents moisture from entering either through a break in the jacket of the electrical cable or between the lid and the box. (In the usual six months between gage installation and nuclear event time, moisture will find its way into every unprotected space.) "Blue quad" is a shielded, four conductor cable with a very tough outer jacket; it survives well in field handling and in grout.

To field the acceleration packages we often attached them to the fiberglass stress paddles. A variation was to encapsulate the aluminum package in a cylindrical epoxy package along with the circular ytterbium cell mentioned above or with a Toadstool stress gage. Other times, we were interested in radial, transverse, and vertical components of acceleration. Here a slightly larger aluminum box was used and three, orthogonally oriented, sensors were packaged in the box. Operationally, these packages and sensors worked well; rarely did a failure occur between installation and event time.

The last gage packages discussed here are the Toadstool and Pancake gages designed and built by

1. In 1987 three video tapes were made by Sandia Division 7116 that show the gage construction techniques. The 11/9/87 one shows procedures for assembling accelerometers, the 11/87 one shows paddle gage techniques, and the 9/87 is labeled "The Making of Ytterbium Flatpacks and Slugs". These tapes are currently stored in the Sandia TIP library. 
Sandians C.W. Cook and Ed Ames. These gages consist of a thin fluid layer sandwiched between two thick aluminum disks. For the Toadstool, a cylindrical "handle" is attached perpendicular to the surface of the disks - the resulting shape resembles a mushroom. For the Pancake, the handle is attached to the side; the two variations allow installation in radial and transverse holes. Inside the handle is a commercially made pressure sensor (Kulite) which is in contact with the silicon oil between the plates. Pressure transducers are available for these packages that span the peak amplitude of 1000 to 30,000 pounds per square inch. Typically we used these gages when the expected stresses were below a kilobar; at these levels the sensitivity of ytterbium is low.

\section{Fielding Aspects}

The major concern in fielding gage packages is the presence of air-filled voids in the vicinity of the gage; these voids perturb stress and acceleration fields. The voids may occur as a result of a poor choice of the orientation of the emplacement hole or from poor grouting procedures. Also addressed in this section is the selection of grout properties.

The emplacement hole orientation to avoid is horizontal, for air pockets are invariably trapped in the crowns of these holes during the grouting operation. We have successfully used numerous holes that dipped as little as five degrees below horizontal. Gage packages are typically located near the ends of the holes. Also inserted in a hole is a plastic pipe, typically PVC, that extends beyond the gage package. Grout is pumped through this pipe. When the hole is nearly filled we slowly withdraw this pipe. We also add a few gallons of water to the hole prior to grouting. The water floats on the grout and wets the surface of the hole as the pumped grout displaces the water. Without the wetting, the viscous grout tends to trap air pockets along the wall of the hole. We have mined to numerous of these grouted holes after events and found very few deviations from intimate contact - and usually bonding - at the grout-rock interfaces. One also needs to carefully monitor the grouting operation. For example, if the hopper above the grout pump is allowed to empty, air bubbles may be pumped into the hole.

Using vertical (or near vertical) "down" holes works well for there is little chance of trapping air in these. Again, grout is pumped into the hole via a pipe and displaces the added water.

Vertical "up" holes are more complex to successfully grout gage packages in them. One needs a "packer" just inside the collar - the entrance - of the hole. The packer consists of rags or porous foam that has been soaked with a quick setting cement. Passing through the packer are two plastic pipes and the gage cables. One pipe extends to the upper end of the hole and serves as an air vent; usually the gage package is attached to this pipe. The second pipe extends just through the packer; the grout is pumped through this pipe. Again, a few gallons of water are pumped in first to "slick" the walls. The grout is pumped until undiluted material exits the vent pipe. Drill holes sometimes intercept fractures that the grout can slowly seep into, thus it is wise to locate the upper end of the vent pipe, and thus the initial upper level of the grout, well above the gage package. We have typically used 1 to 1.5 meter separation between the two.

The proceeding paragraphs apply to 10 meter or shorter emplacement holes that are oriented perpendicular to a radial from the work point, i.e., tangential to the cavity wall. Long emplacement 
holes that are oriented radial to the W.P. have also been used on the DNA nuclear events. Often they were cored holes drilled to obtain samples to characterize the material properties and geology of the site. Usually they were collared 100 to 200 meters from the W.P. and initially dipped about 5 degrees below horizontal. Portions of these holes would then be reamed to 8 inches $(20$ $\mathrm{cm}$ ) diameter and long gage arrays were installed in them. The array consisted of a 2 inch $(5 \mathrm{~cm})$ plastic pipe, aluminum gage fixtures, and gage packages. The fixtures held the four inch $(10 \mathrm{~cm})$ diameter cylindrical gage packages to the plastic pipe. Grout was pumped through the pipe to the far end and displaced water as it slowly filled the long hole.

Figure 2 shows stress waveforms from this type of gage installation. The event was MISTY

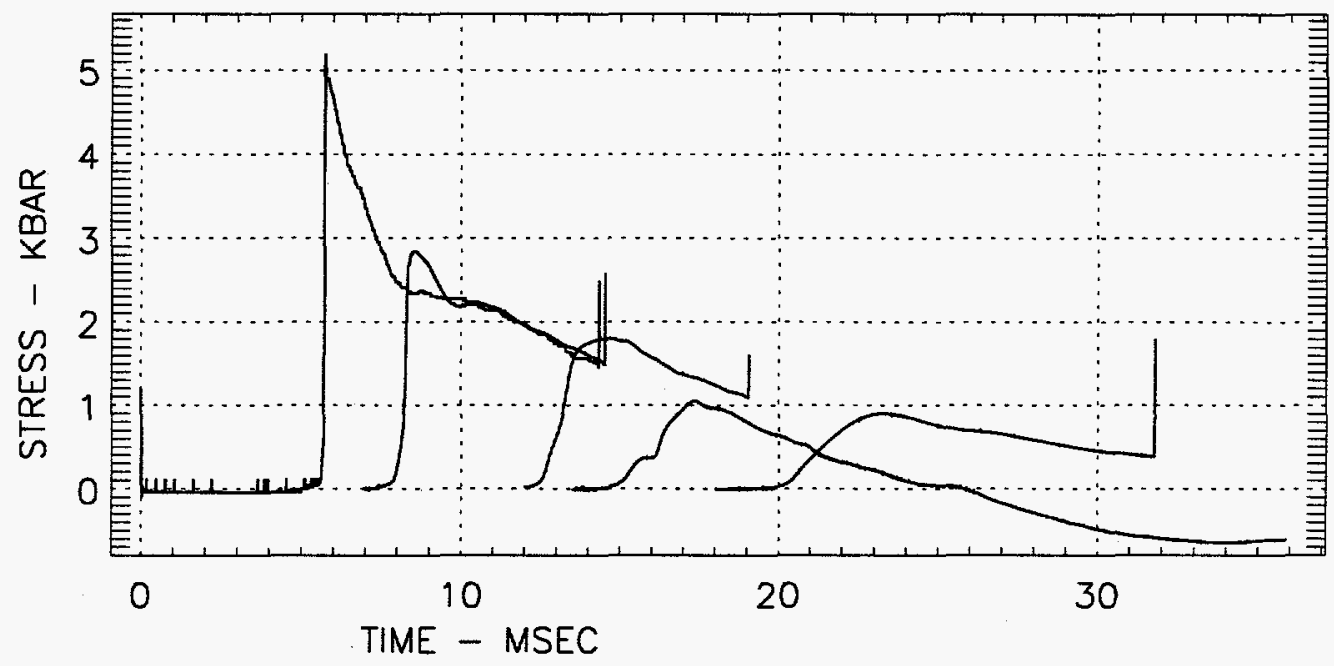

Figure 2. Waveforms from Radial Hole Installation-MISTY RAIN

RAIN; the drill hole was 580 feet (177 meters) in length. Except for the fourth waveform the traces came from YBFC gages. The fourth trace came from a grid that was encapsulated in epoxy without the fluid cell. We suspect the negative amplitude is related to the lateral strain - the spherical divergence effect - discussed earlier. With long risetimes this effect may have also reduced the peak amplitude.

The old approach to selecting a grout was to chose one, or have Waterways Experiment Station (WES) design one, whose mechanical impedance - density times sonic wave speed - matched that of the host rock. The classic NTS grout of this type is HPNS2 ${ }^{1}$. The desired density was achieved by using barite in the grout mix. HPNS2 contains no sand, thus almost any pump can be used to handle it. Sanded grouts require special pumps; also, one should avoid reducing unions and other constrictions that can easily plug the system. Virtually all of the long, radial instrument holes on DNA events were filled with HPNS2. In the inclusion section we will discuss a potential disadvantage of this grout and the radial gage arrangement.

1. Grout names are often associated with events for which they were developed. For example, the HP in HPNS2 refers to the HUSKY PUP event. 
One of the topics we explored when we reviewed gage response problems was grout properties. Specifically, we desired the properties that would yield similar stresses in the grout as those in the host rock. Pacifica Technology (Swan and Patch, 1986) tackled this problem with calculations; they showed that similar stress states were achieved when the bulk modulus, i.e., volume compression, of the rock matched that of the grout. Uniaxial strain tests showed that grouts exhibit a notable volume change when they yield. Tuffs also show this change, but because of the high water saturation in the tuff, the volume change is significantly less. Our solution was to restrict ourself to a limited stress range and use a grout with a yield well above that of the tuff and see if the volume change of the quasi-elastically responding grout was similar to that of the tuff. WES designed a grout, called GSHSG ${ }^{1}$, and its subsequent modifications, that met the criteria. It has an initial bulk modulus of 250 kilobars and slowly "softens" as one approaches and exceeds 0.6 kilobars. Nearly saturated tunnel tuffs show a variation of loading responses; the GSHSG response lies well within the tuff variation. Note that these "matches" were made on the basis of laboratory, four kilobar peak, quasi-static, uniaxial tests. We will return to this point in the gage inclusion section. WES grouted many of our 10 meter transverse holes with this material from the MISTY ECHO event in 1988 to the present.

\section{Gage Power and Recording Band Edges}

Transducers for the Toadstool and Pancake gages and accelerometers are commercially available, bridge type devices powered by standard, constant voltage supplies. The sensitivity of these gages is a linear function of the applied voltage. One needs to calculate the voltage loss in the cable between the power supply and the gage and adjust the voltage at the supply to obtain the desired 5 or 10 volts at the transducer. Alternatively, one can calculate the reduced voltage at the gage and recalculate the sensitivity.

For ytterbium gages we have principally used a Sandia built power supply. It consists of a constant current supply located in one arm of a bridge circuit. The bridge balances out the IR voltage through the gage; thus the voltage out of the bridge is directly related to the stress induced, resistance change. For a calibration step we add a precision resistor in series with the grid simulating a stress induced resistance change. This scheme works well except when using calibration resistors on the order of one ohm and smaller. In this case one needs to take into account the contact resistance in the relay that is used to add the calibration resistor to the circuit.

The constant current supply was designed to be used for stress pulses with millisecond risetimes or when the supply is located close to the gage. There is no provision in the supply to electrically terminate the cable. For pulses with millisecond risetimes, there is time for the gage to come to electrical equilibrium with the power supply. With microsecond risetimes, however, laboratory tests showed a ringing phenomena as the circuit comes to equilibrium. We suspect that some of our older data contain a modest overshoot of the first peak. Our recent "fix" for this effect on close-in gages has been an RC shunt at the power supply end of the gage cable. Laboratory tests showed that $100 \mathrm{ohms}$ in series with about 0.05 microfarads eliminates the overshoot and ringing.

1. This grout name is an acronym from $\underline{G}$ tunnel $\underline{\text { Super }} \underline{\text { High }} \underline{\mathrm{S}}$ trength $\underline{G}$ rout. 
The response time is degraded to about five microseconds with this technique. (The appropriate size capacitor varies with line length.) The shunt circuit works in the following way: at high frequency the reactance of the capacitor is low and the line is effectively terminated by the 100 ohms, its characteristic impedance. At lower frequencies the capacitor acts like an open circuit.

On the DIAMOND FORTUNE cavity event we used a scheme where the gage cables were terminated at the gage supplies with $100 \mathrm{ohms}$. We were concerned about EMP effects entering the gage circuitry and blanking out the recording electronics throughout the timeframe of the stress pulse. The $100 \mathrm{ohms}$ provides a low resistance shunt that allows rapid recovery from the EMP noise. Now, however, there are two current paths loading the power supply. As the gage resistance increases due to stress, the current through the ytterbium grid decreases and that through the $100 \mathrm{ohm}$ termination increases. Now the recorded voltage is no longer linearly related to the stress-induced resistance change. With circuit analysis, however, we derived a formula that related measured voltage to stress induced resistance change. The latter was incorporated in a data reduction algorithm. The disadvantage of this approach is that one needs an accurate measure of all the circuit elements; also, one loses gage sensitivity.

A better scheme to avoid line reflections for fast risetime pulses is to use a constant voltage bridge. High frequencies pass through the low impedance voltage supply and "see" the $100 \mathrm{ohms}$ that one uses in the appropriate leg of the bridge. $(100 \mathrm{ohms}$ is the characteristic impedance of the usually used electrical cable.) DeCarli at SRII has successfully used this scheme; see for example, DeCarli et al. (1992). For noisy environments he used a pulsed version of this bridge. The voltage supply is a charged capacitor which is triggered by an SCR device. At high current level, however, one will see a rising baseline which is the result of the increasing resistance of the ytterbium grid due to $\mathrm{I}^{2} \mathrm{R}$ heating of the grid. This effect can be recorded during a dry run and a correction applied to the event data.

In this section we also want to pass along our rules of thumb for setting band edges on recording equipment. With well known geometries, for example, stress gages on a traditional LOS event, we have set the band edge to be at least twice the prediction. If a second channel is available, we will set that band edge to 2.5 to 3 times the prediction. Twelve bit recording offers far more resolution than eight bit recording. This is a factor in evaluating trade-offs between band edge locations and resolution.

Traditionally we have set the zero voltage baseline half way between the negative band edge and the positive band edge. On the past few events we have offset the baselines for ytterbium gages; the stress induced response is positive which may be confirmed with the calibration step. We located the baseline one fourth of the way from the negative band edge to the positive band edge, thus three quarters of the available recording amplitude is available for the waveform.

And a final comment on band edges for stress gages. On DIAMOND FORTUNE one gage trace "bumped" the band edge. Adequate range had been allowed for normal circumstances but at zero time the traces jumped up and maintained a positive offset. The offset was significant for it was about a half of available recording amplitude. Because the gages were close to the grout surface, we speculate that the neutron flux from the nuclear detonation heated the ytterbium grids which, in turn, increased their resistance, and raised the baselines well before the shock arrival. 
Our rule for acceleration measurements on LOS events has been to place the band edge at three times the prediction. For lesser known event geometries we agonize about bumping the band edge and losing peak amplitudes, versus recording signals that approach the noise level. Because the initial positive acceleration is followed by a negative phase, no offset of the baselines from midband are used for accelerometers

\section{Data Reduction}

Virtually all field measurements are recorded as voltage versus time and subsequently converted using a preshot calibration step to a measured quantity versus time. The voltage from accelerometers is readily converted to acceleration, for the acceleration amplitude is linearly related to voltage amplitude. The calibration step is a generated voltage that is equivalent to a specific acceleration amplitude. For a ytterbium sensor the conversion is more complex. By use of a calibration step the voltage is directly converted to a resistance change. The conversion of resistance change to stress is nonlinear and also depends on how the ytterbium is mechanically loaded.

Stress or pressure causes a resistance change in ytterbium. If a $20 \mathrm{ohm}$ ytterbium grid is loaded to 10 kilobars, its resistance will increase to about $40 \mathrm{ohms}$. This significant change makes it a useful transducer. The quantity "delta R/Ro" is the resistance change per unit of initial grid resistance, that is,

$$
\text { delta } R / R o \equiv(R(t)-R o) / R o .
$$

Here $R(t)$ is the varying grid resistance and Ro is the initial grid resistance; 40 and 20 ohms, respectively, in the above example. The resulting delta $\mathrm{R} / \mathrm{Ro}$ is unity in this example.

As described in the previous section, a calibration step is readily generated for ytterbium grids by adding a resistor in series with the grid. For the above example one would use a resistor of about $20 \mathrm{ohms}$, i.e., a value reasonably close to the expected resistance change induced by ground shock. The calibration step is typically applied to the recorded voltage, thus the data the experimenter receives is resistance change (delta $R / R o$ ) versus time. Now we need to convert this quantity to stress.

For fiuid coupled grids the loading is hydrostatic. Up to 7 kilobars we use the following formula; here, and in subsequent formulas, the stress units are kilobars,

$$
\sigma=2.15\left[(38+93.2 \text { delta } R / R o)^{0.5}-6.1644\right]
$$

This formula was extracted from Lilley and Stephen's fit to their hydrostatic data described in the gage package section. Numerous experimenters have also loaded ytterbium hydrostatically and found negligible deviations from the Lilley and Stephen's data, see for example, Keough et al. (1986). Deviations are almost invariably the result of temperature increase during compression, for the resistance of ytterbium is a function of pressure and temperature. Hydrostatically loaded 
ytterbium shows no hysteresis on unloading, thus the above formula can be used for the complete waveform.

If one has fielded a ytterbium grid sandwiched between pieces of fiberglass board, i.e., the original paddle configuration, the following equation is appropriate to convert the loading resistance change to stress,

$$
\sigma=1.082[1.0-\exp (-20.8 \text { delta R/Ro })]+9.168 \text { delta R/Ro. }
$$

This is Ginsberg's fit to his gas gun data (Ginsberg et al. 1973). In that work the ytterbium grid was mounted in thin fiberglass layers; the loading is believed to be uniaxial strain. From the peak level Ginsberg showed that the unloading is linear and of the following form,

$$
\sigma=\mathrm{A} \text { delta R/Ro }+\mathrm{B} \text {. }
$$

The B "offset" is a hysteresis effect that occurs when ytterbium is loaded uniaxially and yields plastically. Ginsberg's document shows the size of the unloading offset as a function of peak stress. The A coefficient can be obtained by using the exponential loading formula to calculate the peak stress associated with a given peak resistance change, the B coefficient from Ginsberg, and then solving the above formula for $\mathrm{A}$.

The above two formulas for ytterbium, loaded in uniaxial strain, are applicable in the range of zero to 10 kilobars. Above this level Ginsberg suggested the following polynomial,

$$
\sigma=13.65(\text { delta } R / R o)-4.358(\text { delta R/Ro })^{2}+0.9227\left(\text { delta R/Ro) }{ }^{3}-0.0684(\text { delta R/Ro })^{4}\right. \text {. }
$$

Again, this is a fit to gas gun data at higher stress levels and is consistent with the earlier dynamic work by LRL and SRI experimenters.

Note that ytterbium has a phase change at 37 kilobars which involves a drastic resistance drop; some workers, however, believe they have seen relatable effects as low as 25 kilobars. In this stress regime, then, one needs to make duplicate measurements with manganin grids.

Finally, we need to treat the case where the fluid coupled grid is used at levels above 7 kilobars the upper limit of the Lilley and Stephens work. This case was discussed in an internal Sandia memo written for data reduction on the Non Proliferation Experiment. Words from that memo follow. In addition to their hydrostatic work Lilley and Stephens also loaded ytterbium in a "piston and cylinder" system to 40 kilobars. They adjusted this data to agree with the hydrostatic data at 5 kilobars and call it "relative resistance" versus pressure data. Later in their paper they state "we believe that the pressures in our piston-and-cylinder system are closer to hydrostatic than those in the systems used by other workers." Four of the Lilley and Stephens data points are shown as squares in figure 3. The second data set - marked with Xs - are unpublished data that were obtained by Len Hansen (Sandia, Department 1151) and the author using Department 1151 's 30 kilobar pressure vessel in January 1989 . We loaded a ytterbium grid hydrostatically in pentane at 19.5 degrees $C$ to a pressure of 22 kilobars. The pressurization was achieved after a number of previous attempts in which grids or leads failed. Also shown in the figure are four data 


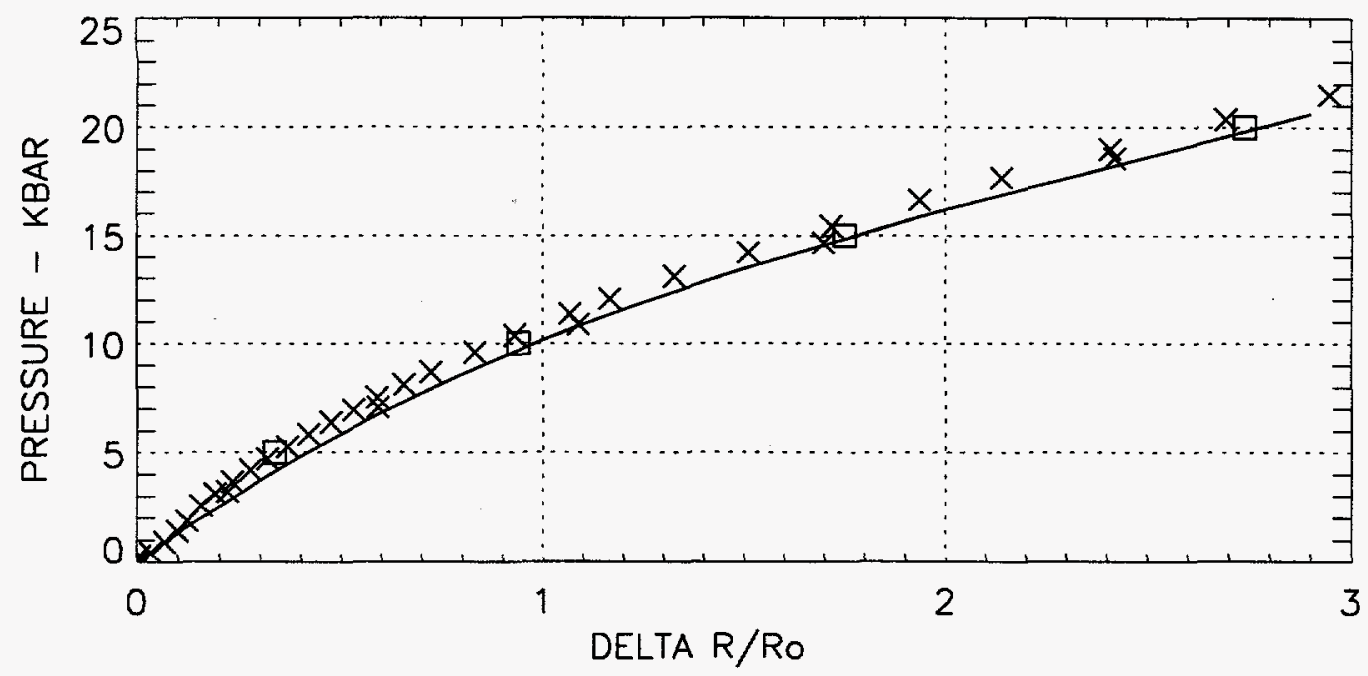

Figure 3. Ytterbium - Pressure Versus Resistance Change

points, also marked with Xs, that lie below the locus described by most of the other Xs. These are data obtained on the unloading cycle. The solid curve in the figure is Ginsberg's polynomial fit to the gage gun data given above. Above the 7 to 10 kilobar level, the Sandia pressure vessel data, the LRL quasi-hydrostatic data, and the fit to the gas gun data are within a few percent. To a good approximation one can use the polynomial to reduce fluid coupled data, and one-dimension loading data, above 7 to 10 kilobars. (At the one kilobar level, however, the one dimension loading induces only $65 \%$ of the resistance change induced by hydrostatic loading. Thus, at the lower stress levels one needs to use the earlier given formulas.)

\section{Gage and Cable Survival}

Stress waveforms from older explosive events in tuffs typically showed a rise to the peak, and varying amounts of the unloading waveform before gage or cable failure occurred. Calculators modeling these events, however, wanted more of the unloading portion of the waveforms to compare with their work. The real push for extending lifetimes occurred when the concept of a residual stress field was proposed. The containment community wanted measurements to confirm its existence, to compare its amplitude versus range with calculations, and to observe the decay of the field with time. In this section we discuss topics related to gage and cable survival, that is, items needed to obtain more of the waveform. First we discuss general topics: observations on gage lifetimes, pre-shot geology work, and the time domain reflectometry (TDR) technique. Then we review gage and cable failure work on a series of tunnel events. Re-entry work has contributed to the understanding; we describe observations on DISKO ELM. Finally, we discuss balancing the compression of a radially oriented cable against the lateral strain of a transversely oriented cable in an attempt to achieve a condition of near zero cable strain. Although we have explored the problem and extended gage lifetimes, additional techniques are still needed to obtain waveforms to late times. 
Gages fielded in the saturated tuffs at NTS that show peaks in the range of 0.2 to 0.4 kilobars usually survive ground shock and show amplitudes to the end of the recording intervals. Post-shot resistance measurements often show these gages and their cables to be intact. As one moves closer to work points, however, gage and cable lifetimes decrease. Note that it is most likely the displacement induced by the passage of the stress wave and not the stress amplitude that causes failure.

The geologic mapping by the $\mathrm{RSN}^{1}$ geologists has been very useful in the study of gage and cable survival. As pipe and bypass drifts were driven, the geologists investigated and mapped the exposed fractures and faults. With this knowledge we often modified gage plans, for example, moving a proposed gage location to the portal side of a mapped fault. (The geologists noted a major fault on MISTY ECHO. We instrumented this one to measure the time when it moved.) Post-event we have correlated the mapped fault locations with the cable break locations shown by the time-domain-reflectometry (TDR) measurements.

In the TDR technique a short electrical pulse is injected into an electrical cable and displayed on an oscilloscope. Cable splices, connectors, and shorted or open ends of cables reflect a portion of the electrical pulse. The oscilloscope display shows these reflections as a function of time. One dials in the propagation constant for the type of cable and the horizontal display is read in feet, that is, the distance from the instrument to the reflecting item. We have used the portable Tektronics Model 1503B TDR unit. We measure the cables pre-event from a location outside of the end of stemming and measure them again post-event. In the early work we noted the distance to the cable breaks from the display; later we recorded the TDR waveforms on a portable computer. Subsequently one can display both the pre and post-shot traces on the screen and note the changes. The major limitation of the TDR technique is that it only shows the cable break closest to the unit. Thus, for the work in the tunnel, no information is obtained about additional cable breaks closer to the work point.

\section{MISSION CYBER}

Cable protection schemes fielded on the MISSION CYBER event consisted of hydraulic hose on some gage cables and thick wall pipe protection for a series of cables in the bypass drift. Gages survived that saw 0.25 kilobars or less. For the two gages that measured between 0.7 to 0.8 kilobars, the gage with the hydraulic hose lasted until 78 milliseconds after zero time; the gage without the hose ended at 29 milliseconds. This suggested that hydraulic hose protection lengthens data lifetimes but does not prevent cable failure. The pipe gages consisted of a gage package mounted on the end of long lengths of type 4130 steel pipe. This thick wall pipe was 2.5 centimeters in outer diameter and 0.6 centimeters inner diameter. The sections of pipe were joined with high strength couplings. (This is the type of pipe we had successfully used for cavity pressure measurements on high-explosive experiments.) One pipe sheared at a grout-tuff interface during the rising portion of the stress waveform. Here the predicted stress was 3.7 kilobars. The others pipes saw lower stresses and survived. Thus, the pipe technique was promising for cable survival. At that time, however, it was considered cumbersome. The transition from pipe to gage package had not been successfully developed, and the long, open pipes were a containment concern. In

1. RSN - Raytheon Services of Nevada was formerly Fenix \& Scisson, Inc 
using the TDR unit on this event we were surprised to see only \pm 20 feet resolution; however, this represents a $\pm 5 \%$ error.

\section{DISKO ELM}

On DISKO ELM we fielded a series of gages in holes drilled out of the bypass drift. Electrical cabling consisted of ordinary TSP from the high pressure alcove to the gas block, stretch TSP to a junction box near the gage holes, and teflon insulated TSP in stainless steel tubes to the gage packages. (TSP is twisted shielded pair cable. Stretch TSP consists of 6 shielded pairs spiraled about a soft inner core and was designed to stretch axially at least $20 \%$ before damage to the conductors.) The different types of cables complicate TDR measurements for they have different propagation constants. Ordinary TSP shows a constant of 0.66 , that is, the speed of an electrical signal in this cable is two thirds the speed of light. The constant for the teflon insulated cable is 0.71 . Stretch TSP shows a value is 0.44 ; this slower value reflects the 1.5 times longer cable length - wound in a long spiral path - than the linear length of the cable. Splices between these cables reflect a bit of energy that is seen on the TDR display. This helps identify locations and provides some comparison between electrical and physical lengths.

TDR work after the DISKO ELM detonation showed that the cabling to these gages was intact to about the location of the junction boxes. The boxes were at the nominal 1.2 kilobar level suggesting that the stretch TSP provided some improvement of cable survival times. Pre-shot geology

mapping showed approximately vertical fractures that crossed the bypass drift at about right angles to the axis of drift. Thus, the fractures nearly "faced" the wavefront; this orientation should have minimized differential motion on the fractures.

Gages in long radial holes on this event were fielded with hydraulic hoses protecting their cables. Gages that measured 0.5 kilobars or less showed survival, however, there were no mapped faults behind these gages. Waveforms from closer gages showed lifetimes that correlated with range. The best analytic fit to this lifetime versus range data was $\log -\log$ and showed lifetimes proportional to the range raised to the 3.3 power. Thus, doubling the range from the work point to the gage location increases the gage lifetime by a factor of ten.

Gages on the LOS pipe in front of the FAC on this event had no cable protection; only early time data was needed from them. The cables were routed down the LOS drift, out the FAC cross-cut drift and along the bypass drift. Post-shot TDR work showed that these cables broke at three locations. Two cables were severed about half way along the FAC cross-cut drift and within the TDR error of two fractures mapped preshot. On mineback, RSN geologists noted differential displacements of nine centimeters on the fractures. Two other cables showed breaks near the intersection of the FAC cross-cut and the bypass drifts. These may have been caused by differential motion across the grout interfaces or bulkheads. The remaining cable showed a break farther back in the bypass drift and at the nominal 0.4 kilobar stress level.

Combining the gage and cable analysis from DISKO ELM with previous work, we developed the tentative hypothesis that gage and cable failures are related to differential displacements across faults and fractures and, perhaps, at bulkheads and other man made interfaces, at least, out to about the 0.5 kilobar stress level. Motions of the rock at greater ranges occur but perhaps this is 
the farthest extent of differential displacements. There was also evidence suggesting that some amount of cable protection lengthens gage and cable lifetimes. As one approaches the work point, however, the increasing motions will destroy even the strongest scheme, for example, the 4130 steel pipe scheme fielded at the 3.7 kilobar level on MISSION CYBER. It was also evident that there is notable, unexplained erraticness to cable survival. We began to understand that "threats" to cables are difficult to quantify.

Also on this event we discovered that gage packages can contain failure modes. In fabricating the ytterbium paddles, the stainless steel tubing that serves as a handle and contains the electrical cable was flattened to fit between the two epoxy-fiberglass boards. This partially crimped the twisted pair cable in the tube. As seen in the recorded waveforms, the arriving stress wave completed the crimp and electrically shorted the grid shortly after the time of the peak stress.

\section{MINERAL QUARRY}

The next event was MINERAL QUARRY. Gage and cable survival was strongly affected by two faults that crossed the bypass drift; one was at the nominal 1 kilobar stress level, the other was at the 0.5 kilobar level. Three gage records ended 4 to 6 millisecond after time of arrival of the stress wave; we suspect movement on the closer fault severed their cables. The record from the fourth gage of the group, however, shows a lifetime of 36 milliseconds. Post-shot TDR work showed, with one exception, that all cables were severed at the location of the 0.5 kilobar fault. Again, we suspect differential displacement across faults. The exception was a cable that was intact to about the location of the closer fault.

Pre-shot geology work showed the 1 kilobar fault passing near the collar of the radial IH1 hole. Spanning the location we fielded a "tub" of fluid and snaked about a half meter of gage cable in the fluid. The intent was to allow fault motion to shear the tub and have the cable move through the fluid. The tub, two cubic feet in volume, should have allowed about a foot of offset on the fault before cables would be cut. As noted above, the TDR work showed that cables were lost at the 0.5 kilobar fault, thus, precluding our examining the survival of the cables in the fluid. The record from the gage in the $\mathrm{IH} 1$ hole, however, gives some information. The waveform ends shortly after the stress wave is calculated to have passed the fluid tub. This implies that stress induced, fault motion severed the cable to the gage. Perhaps the fault offset was greater than allowed for in the fluid tub or the fault moved on a plane parallel to the one mapped preshot, that is, it missed the tub. Reentry was not performed on MINERAL QUARRY, thus we were unable to examine displacements across the critical faults and examine the failure of the tub technique. The two exceptions - the 36 millisecond record and the cable that survived the 0.5 kilobar fault movement mentioned above - suggested that we were on the "ragged edge" of cable survival and that some sort of armored cable might increase gage lifetimes.

On these events the Santa Fe office of Science and Engineering Associates (SEA) had been fielding a special stress gage (CALIP) which allowed post-event calibration of the gage (Keller 1988). The Achilles' heel of that work was the survival of electrical and fluid connections to the special package. Carl Keller, then of SEA, and Gary Greenfield of SRI International, developed the idea for an armored cable and SRII fabricated the cable. It consisted of a standard electrical cable, RG22 for example, armored with wire rope. Anti-rotational wire rope consists of an inner core 
with the strands spiraled in one direction and an outer layer with strands wrapped in the opposite direction. The Keller-Greenfield technique involves removing the outer layer of strands and hand wrapping them on the electrical cable. Typically the diameters are 11 millimeters for the electrical conductor and 19 millimeters for the overall assembly. The wire shield consists of 11 strands, each about 4 millimeters in diameter, that spiral about the electrical cable. We contracted with SRII to cast armored cables, along with bare cables, in blocks of weak and strong grout. They then loaded them in shear, both quasi-statically in a large press, and dynamically with explosives. The results showed seven to nine times more shear strain to failure of the armored cable than the bare cable. On the DISTANT ZENITH event we fielded a number of short lengths of the wire rope cable in conjunction with a self contained recording package (SCEMS). The SCEMS concept was to minimize cable lengths and record data close to the gages. On this event, however, the batteries in the SCEMS unit were apparently unable to survive the heat generated by the curing of the grout host. We continued with the wire rope scheme on the HUNTERS TROPHY event.

\section{DISTANT ZENITH}

Cable hardening on DISTANT ZENITH consisted primarily of using stretch TSP and discrete cable hardening where cable bundles in the bypass drift crossed mapped faults and fractures. The discrete hardening comprised a meter long section of cables wrapped with soft, rubbery "curlycues". These spiral shaped items are normally used to separate cables in gas block regions and are about 7 centimeters in diameter and length. On either side of the wrapped assembly we added meter long rock bolts and taped the assembly together.

The post-event TDR work showed that all the cables in the bypass drift that passed or entered the FAC crosscut drift were severed at the intersection of these two drifts. Cables behind this location were intact. This event was reentered and a reverse fault of 0.4 meter displacement was found in the grout stemming at that location. The strike of this unusual fault was parallel to the tunnel axis and the fault was confined to the grout stemming. Although the predicted stress at this location was 0.75 kilobars, extrapolation from gage records suggest that the location experienced about 0.3 kilobars. There was a major fault at the 1.5 kilobar range that showed discontinuously open sections. Measured stresses immediately behind this fault showed peaks of about $40 \%$ of prediction. There was an exceptional record from one gage on this event. The gage was located in the radial IH2 hole; its waveform shows a peak of 3.8 kilobars and a lifetime of 46 milliseconds.

\section{HUNTERS TROPHY}

On HUNTERS TROPHY we fielded numerous lengths of cable protected with wire rope. One of our associates, Rod Shear, suggested having a wire rope manufacturer fabricate the cable. Hand building any significant length of the cable is laborious - the cable is coated with an antirust compound, the tough steel has to be cut strand by strand, and the sharp ends of the wires regularly gouged the person working with it. We visited Wire Rope Corporation of St Joseph, MO and planned a fabrication scheme with their engineers. Near the end of a production run of an appropriate size wire rope, they would substitute our electrical cable for the inner core and continue spinning the outer layer on the electrical cable. We had wire rope added to lengths of 6 pair TSP, RG22, and Blue Quad cables. 
On HUNTERS TROPHY we fielded stretch TSP cable to the 0.5 kilobar level in the bypass drift and wire rope cables from that location to gage packages in various drill holes. Although an extensive set of dynamic waveforms were obtained from these close-in gages, they did not show significantly extended lifetimes. With one exception, the TDR work showed that cables crossing the intersection of the FAC crosscut and the bypass drifts were severed in that area. This included the wire rope protected cables. The nominal stress level at the breakage locations spanned the range of 0.6 to 0.8 kilobars. The exception noted above was the cable to a gage in the $\mathrm{IH} 1$ hole; that gage produced a record with a peak of 0.97 kilobars and a duration of 0.6 seconds at which time the underground recording equipment lost power. Pre-shot the RSN geologists had mapped two faults that crossed the intersection of the bypass and FAC crosscut drifts. All gages behind this location showed survival both on the recorded waveforms and in the TDR measurements. It appears that the wire rope cable does not survive fault motions. No reentry was performed on HUNTERS TROPHY.

For the N Tunnel events - HUNTERS TROPHY and MINERAL QUARRY - cable survival seems to be controlled by existing faults at the 0.5 to 1 kilobar range. This suggests that stress induced particle motion is sufficient to induce differential motions on these faults. These motions, then, act like guillotines to signal cables, even the armored ones. For P Tunnel events - MISSION CYBER, DISKO ELM, and DISTANT ZENITH - the phenomenology of cable survival is less clear. A motion induced fault in the grout stemming severed cables at about the 0.4 kilobar level on DISTANT ZENITH while cables survived to the 1.2 kilobar level on DISKO ELM. In part the difference between these two tunnels is that in $\mathrm{N}$ Tunnel there are numerous, well developed faults that show pre-event movements of centimeters to meters. Also, fractures and faults are water saturated. In contrast, $P$ Tunnel shows few faults and minor displacements on those seen. Also, the tunnel is above the elevation of fracture saturation; hence the few faults and fractures are dry.

More work is needed on cable survival through fault movements. One scheme holds promise. Laboratory work (Morrill et al. 1981) has shown that cables protected with aluminum tubing will flow through a weak grout when subjected to shearing forces. We proposed that a tunnel filled with a weak grout and crossed by a fault that moves differentially under a dynamic load is a large scale version of the laboratory work. On HUNTERS TROPHY we fielded wire rope protected cables through a section of tunnel that crossed a major fault. This section was grouted with a low strength material called Superlean Grout. Additionally, we located the armored cables in the approximate center of the drift. The post-event TDR measurements showed that these cables were cut by a fault farther from the work point, thus giving no information about the above scheme. Also, we were unable to examine the area post-event for no reentry was performed. Although we were unable to assess the results, we feel that this approach holds promise.

\section{DISKO ELM Reentry}

Information on cable and gage survival at higher stress levels has been difficult to obtain. The TDR work gives information on the outermost cable break only. The close-in waveform itself, gives some information. Using the shown breakage time and the wave speed, one can calculate 
where the wavefront was at the breakage time. This range may be compared to the locations of faults mapped preshot. Another source of information is the occasional reentry on an event. On the DISKO ELM reentry we recovered a close-in, self contained data recording package (SCEMS). Reentry in this area provided useful observations on deformations of cables and tuff loaded in the 2 to 5 kilobar level.

Prior to reaching the SCEMS data package, however, another instrument hole was exposed, mapped, and photographed ${ }^{1}$. The radial $\mathrm{IH} 12$ hole was collared and drilled near the work point end of the bypass drift. The 20 centimeter diameter hole dipped 9 degrees and contained three gage packages. The objective of the measurements was to obtain stress data in the 5 to 10 kilobar range to address questions raised by the MISSION CYBER event. The record from the rear gage (6933) showed an overshoot and subsequent oscillations related to the unterminated cables described in the Gage Power section. Based on knowledge from laboratory tests on the electronics and the approximate cable length, a corrected peak of 5.4 kilobars was estimated.

The outer portion of the $\mathrm{IH} 12$ hole was exposed broadside, that is, the mining direction was nearly perpendicular to the axis of the hole. As shown in the reentry photograph (C-DE-192-1-OUO 19 March 90), the exposed hole, grout, and hydraulic hose containing electrical cables showed no obvious distortion. After recovering the SCEMS unit we returned to the IH12 hole and followed it toward the work point. It was exposed to about 0.5 meter in front of the 6933 gage package. In front of the gage package we noted buckled sections of hydraulic hoses; these were attached to the closer gages. The pneumatic spading tool, used to chip out the tuff in this area, easily "sliced" through the rock; this was clear evidence of shock induced damage (microfracturing) of the tuff. In the 1.5 meters behind the package there were two short range, shear offsets of the stemmed hole and hydraulic hoses. The buckled hydraulic hose showed that a vertical offset of about 15 centimeters had occurred. The second offset was about 0.6 meters behind the first. Viewed from above, this offset was to the left and suggested movement on a vertical plane aligned 30 degrees to the axis of the grouted hole. Between these features the grouted hole and hydraulic hoses were relatively undistorted. The following three FCDNA photographs show views of the 6933 gage package, the hydraulic hoses, and the shear offsets: C-DE-197-1-OUO, C-DE-197-2-OUO, and C-DE-197-3-OUO, dated 27 March 90.

These observations of discontinuous displacements suggest that at the 5 kilobar stress level the tuff does not flow uniformly even though the stress is about ten times the nominal, laboratory determined, yield stress. Additionally, the rock had been notably weakened by shock damage. Although some radial compression probably occurs, the bulk of the material appears to displace outward via movement on shear failure surfaces, and leaves damaged but undistorted rock between the shear planes.

Eight tenths of a meter behind the IH12 hole was the 61 centimeter diameter IH11 hole containing the SCEMS recording unit and a gage package. Figure $4^{2}$ shows a vertical section of the mined

1. Photographic documentation of this work resides in the FCDNA files at Mercury, Nevada. The numbers on a few photographs are given for those who have access to the files and would like to view the details.

2. This figure is a reproduction of FCDNA photograph C-DE-195-4-OUO $22 \mathrm{March} 90$ and used with permisssion. 


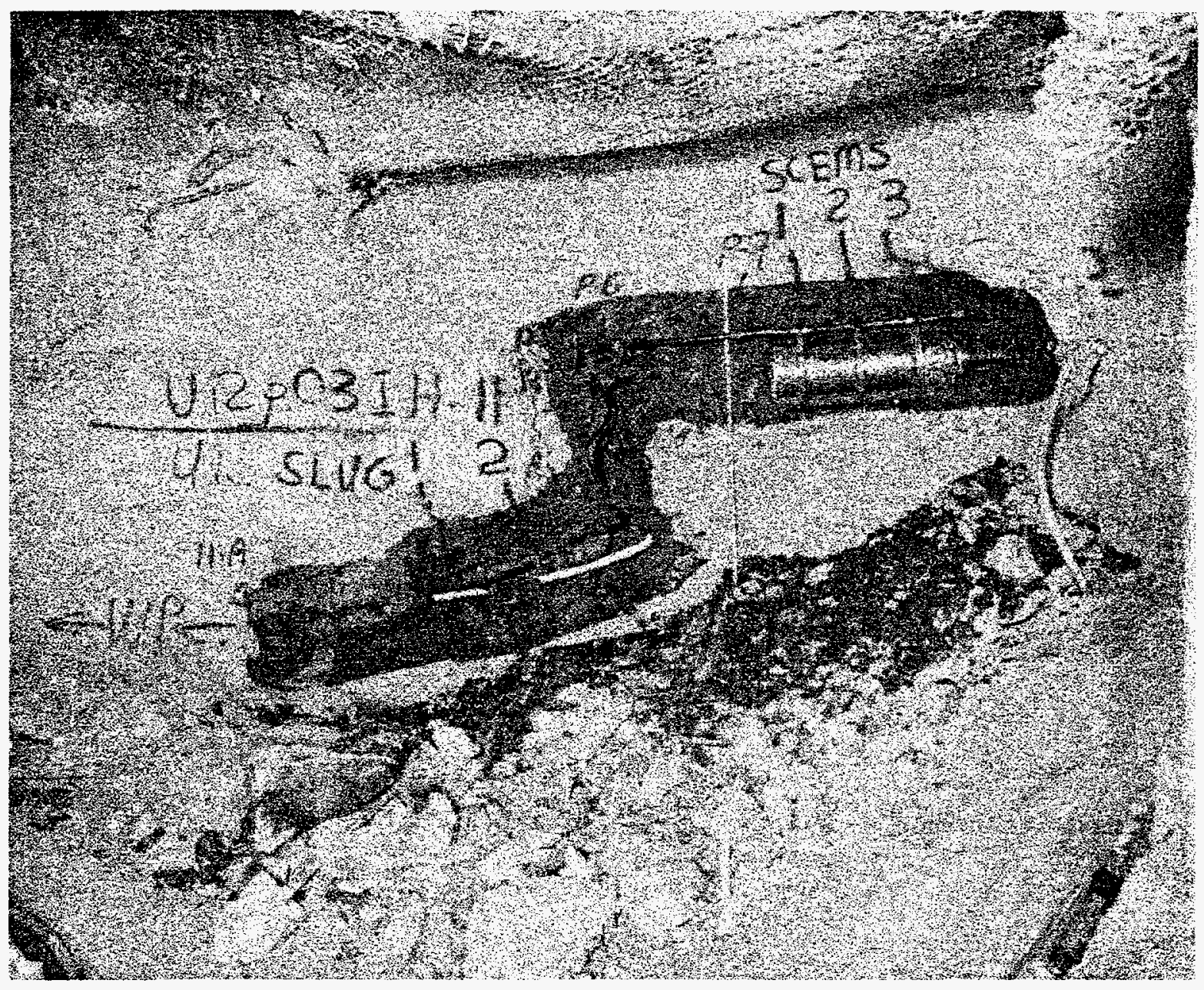

Figure 4. SCEMS Reentry - Vertical Section

out hole; on installation we added blue dye to the grout to readily identify the drill hole during reentry. The notable feature in the photograph is the offset of the grouted hole. Close inspection suggests two shear planes, one where the black steel pipe is bent downward at its left end (near the " $p-6$ " marking), the other where the white plastic pipe bends upward at its right end. There is about a 0.3 meter separation between the shear planes. The total offset on the planes was about 0.8 meters.

The gage package is between the " 1 " and "2" marks in the lower portion of the hole; the SCEMS unit is the cylindrical object in the upper portion. The unit contained gage power, signal conditioning, and a memory. The intent was to record long term gage signals close to a gage in order to avoid gage cables being severed by differential ground motion! The external gage package was remote from the recording unit to prevent the massive package from influencing the stress and motion environment. The external stress gage measured a peak of 2.7 kilobars and showed a lifetime of 3.1 milliseconds. Gage failure time is suspected to be the time of differential movement on the shear planes. The external accelerometer recorded ambiguous data; the internal accelerometer gave a useful trace. The peak was $5500 \mathrm{~g}$ and the recording time was the programed 900 milliseconds. Integration of this trace showed a peak particle velocity of $88 \mathrm{~m} / \mathrm{sec}$ and a rebound time of $146 \pm 9$ milliseconds. The massive SCEMS unit may have affected this internal measure- 
ment. The close-up photographs of the SCEMS package, the grout, and the other hardware show no obvious evidence of differential movement of the package relative to the grouted column. For example, if the motion of the 272 kilogram package notably lagged behind that of the host, we should see buckles in the steel pipe attached to the top of the SCEMS and extending forward toward the work point. This pipe originally coupled the gage package to the SCEMS. One of the steel rings that surrounded the cylindrical package had broken loose and moved about a centimeter from its original position. A rough calculation of the density of the package yields a value of $7.7 \mathrm{Mg} . / \mathrm{m}^{3}$; the value of the host is 1.9 .

Of curious interest is that the fault planes in front of the SCEMS unit did not extend to the previously discussed IH12 hole located 0.8 meters in front of the SCEMS hole. A close look at the photograph in figure 4 suggests that fault motion on the upper plane extends up to the top of the mined out volume. Thus we see a fault trace, or shear plane, above the hole that apparently did not extend out of the plane of the figure to the IH12 hole 0.8 meters away.

\section{Non-Proliferation Gages and Cables}

As a final topic in gage and cable survival, we want to discuss the background for the design of the close-in gages fielded on the Non-Proliferation Event ${ }^{1}$ and show the measured data. The TDR and wire rope techniques are appropriate for the one to two kilobar stress levels where one wants survival to the end of data recording. At higher stress levels survival of cables to late times appears improbable, however, one can explore techniques that may lengthen lifetimes. (Again note that it is probably the strain associated with the high stress that severs cables.) One topic is how to route gage cables to move with spherically divergent flow fields. A radially oriented cable is compressed; a transverse one is stretched by the tensile circumferential strain associated with spherical divergence. Can a cable be oriented such that the two effects are balanced?

Seaman's approach to this problem (Smith et al. 1972) was to assume that the flow is plastic and that negligible volume change occurs. He wrote an expression for the radial and circumferential strain on a cable oriented at an angle to a radial to the work point. He set the net strain to zero and solved for the angle at which this occurs. With the above assumptions the calculated angle is 55 degrees. Based on this analysis we built paddle gage packages in which the plane of the sensing element was parallel to the wave front and the rear, cable transition section gently curved to obtain the 55 degree angle. The field event was Middle Gust I, conducted by the Air Force Weapons Laboratory in 1972. The medium was soft clay. The 20 ton high-explosive charge was placed half above and half below the ground surface. A meter deep trench was dug near the charge location and 20 centimeter "niches" were dug in the wall of the trench. A steel tool, shaped like the bent gage package, was pounded into the clay in the back of the niche. A gage package was inserted into the generated slot. The cable leads were oriented in the backfilled clay in the trench at the 55 degree angle. Two manganin and three ytterbium gages were fielded in the 2.4 to 2.9 meter range and about 0.7 meters below the surface. Figure 5 shows the closest manganin record. The risetime probably has been lengthened by the 1000 meter coaxial cable and there are probably strain effects in the unloading portion of the waveform. The surprising peak and lifetime are 42 kilobars and about 100 microseconds. The other close-in gages also showed similar lifetimes.

1. This N Tunnel event comprised one kiloton of high-explosive. 
We believe that this survival was related not only to cable orientation but also to the plastic flow of the host clay.

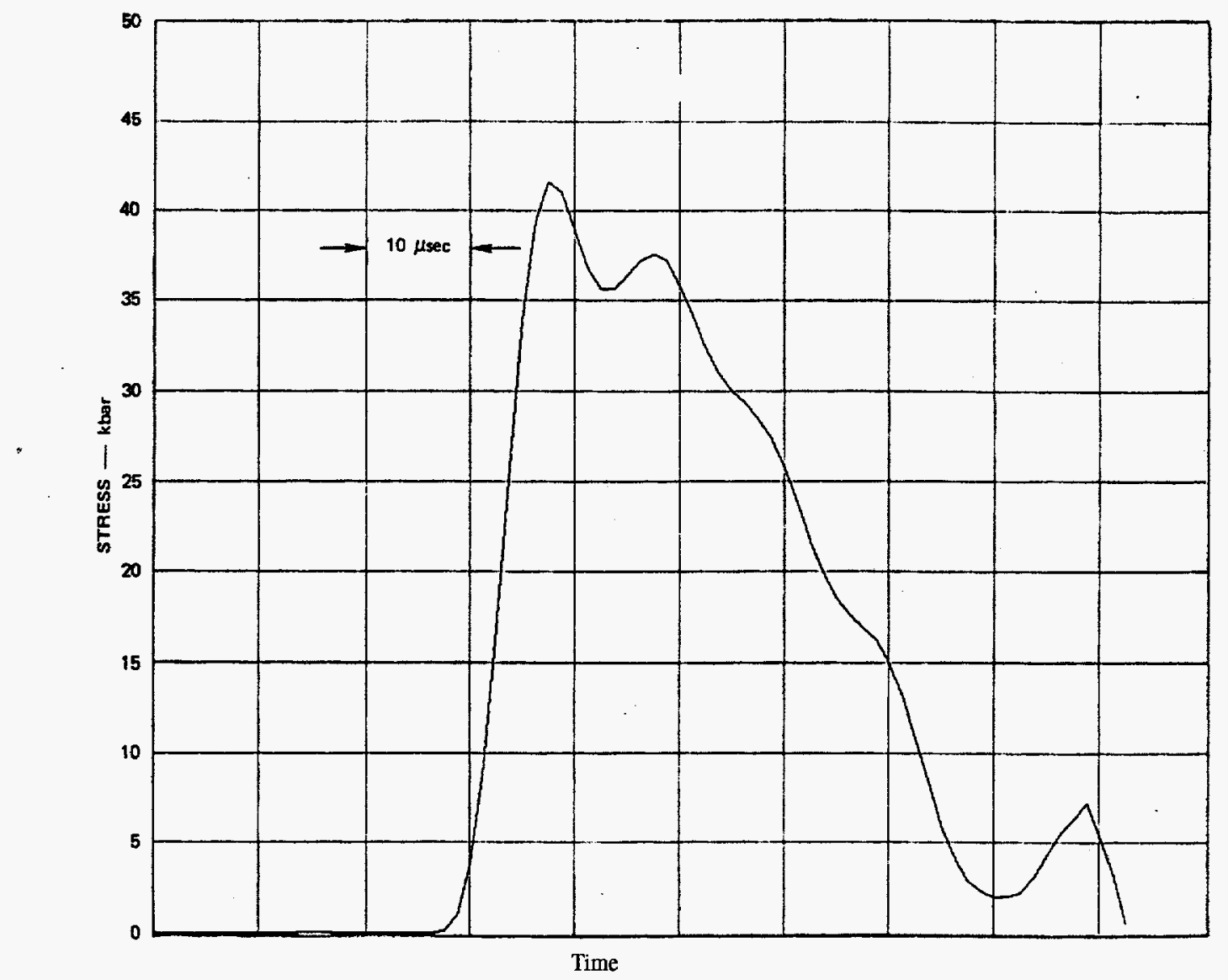

Figure 5. Manganin Gage Waveform - Middle Gust Event 1

The next work in this area was that of Hartenbaum (1978) who did an extensive review of reported measurements on DNA nuclear events, interviewed people working in the field, and performed analysis on cable strains. He wrote expressions for the differential length of a cable before and after displacement including the angle between the cable element and a radial line to the work point. He equated the two and solved for the angle. The result showed that for zero strain each short length of the cable needs to be oriented at a specific angle to the current radial line from the work point. In a plane, this condition required the cable to follow a curved path, specifically an logarithmic spiral.

The next step was to resolve the dilemma of the curved path. It was solved by Carl Keller, then at SEA - Santa Fe. The scheme is simply a helix or spiral whose axis is aligned radial to the work point. The angle between an incremental length of the spiral and a radial to the work point is constant, thus conforming to Hartenbaum's prescription. Further, Keller slowly varied the pitch of the helix with range to account for the decreasing displacement; Hartenbaum's analysis also shows this varying angle. The helix was proposed as a scheme to measure cavity pressure and 
was made of stainless steel tubing. It was successfully fielded on the G Tunnel HALFTON event. Subsequently, SEA fielded the cavity pressure helix on MISTY ECHO and Lawrence Livermore National Laboratory adopted the scheme for measurements on vertically emplaced nuclear events.

The technique is readily adapted to gage cables, that is, slide electrical cable into tubing that has been shaped in a spiral, or spiral the cable about a light weight frame and insert the assembly in a radially drilled hole. On MINERAL QUARRY we fielded a 34 meter long spiral in the 20 centimeter diameter hole IHI. It appears to have survived until fault movement at the collar of the hole severed the cable.

The crux is that where there is a uniform flow field, i.e., in a high stress regime or weak material, orienting a cable to balance the two strains is promising. However, in tunnel tuff, the cable or tubing must traverse the approximately 5 kilobar zone where radially loaded rock exhibits discontinuous shears and displaces at an angle to a radial such as seen on DISKO ELM and reentries on other events. Finally, the "item" must survive the potential displacements on existing faults that are present at the one kilobar level. As stated at the beginning of this section, the attempt was to develop and field techniques to lengthen gage survival times. We have, perhaps, explored the dimensions of the problem.

All this discussion leads us to the close-in gages fielded on the Non-Proliferation Experiment (NPE), nee Chemical Kiloton. Angle holes were drilled for these gages. At the gage locations the axis of the hole made a 60 degree angle with a radial line from the work point. Progressing back from the gage the angle between the cable and the current radial from the WP decreases. Thus we violate the Hartenbaum prescription and the cable saw increasing radial compression. The gage package was a paddle that was parallel to the wavefront. In the cable transition area the paddle bent to conform with the angled hole. (These were known locally as "spatula" gages.) Additionally, we used the wire rope cable described in an earlier section. Figure 6 shows the waveforms from the two special gage packages fielded at initial ranges were 15.3 and 20.5 meters. We see peaks of 16 and 7 kilobars and lifetimes of 5.5 and 6.6 milliseconds. These are significant lifetimes for these stresses and probably represent the state-of-the-art. One could, perhaps, achieve a longer survival time with a massive steel housing or use a large fluid filled hole. The measured stress, however, would be significantly different that the stress in the rock. This is the inclusion problem that will be tackled in the next section.

We write a few more words on NPE for they are appropriate to gage and cable survival. No gages on this event survived to late time. The culprit was that the end of stemming was 84 meters from the work point which is about $70 \%$ of the scaled lengths used on DNA nuclear events. The nominal free-field stress level at this range is 0.3 kilobars. Cables in the open drift were protected with sand bags and mining hose but the protection wasn't sufficient for the high accelerations experienced. Indeed, there was significant collapse of the open drift. Bruce Hartenbaum stated the problem well in his wonderfully titled report, Design of Subterranean Instrumentation Cables to Survive Large Amplitude Ground Motions (Hartenbaum 1978), "The entire cable plant must be considered from the transducer to the recording apparatus to prevent one weak component from causing the failure of the entire data link." 


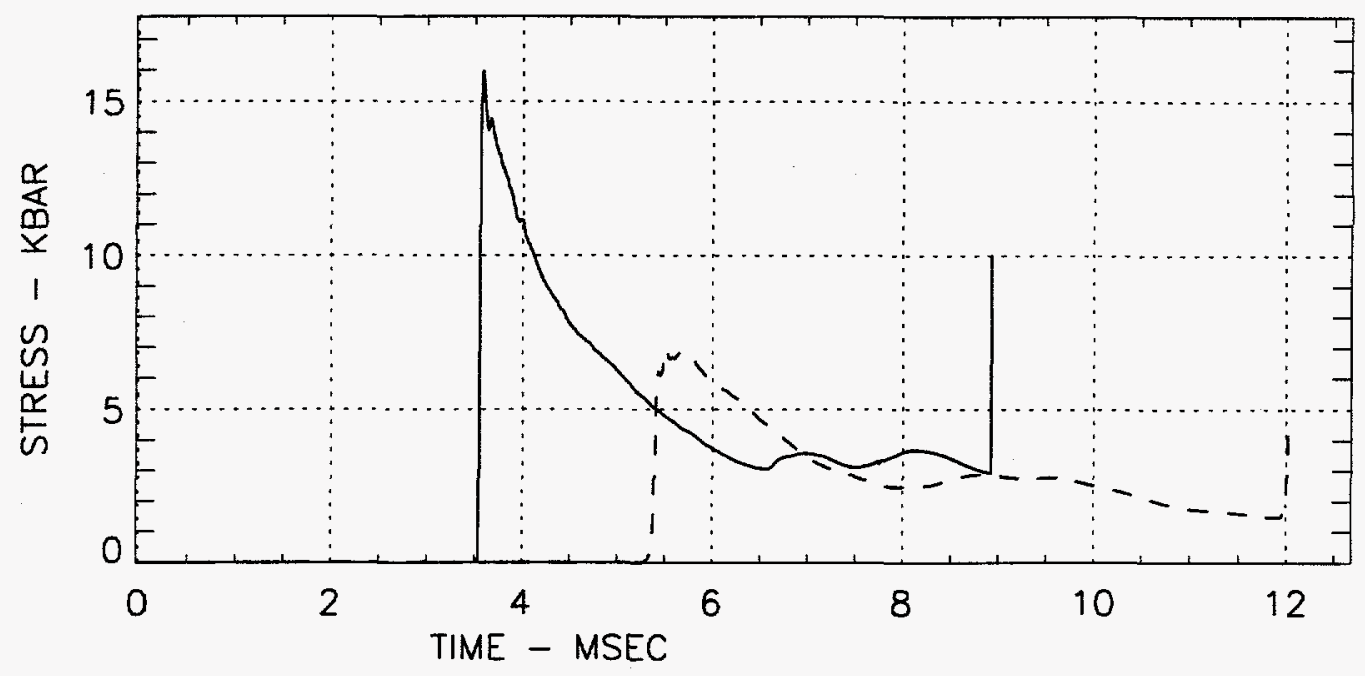

Figure 6. Close-In Waveforms - Non-Proliferation Experiment

\section{Inclusion Studies}

Field measurements of stress and motion are invariably made by installing gage packages in drill holes and coupling the package to the host rock by use of a cement-based grout. Measured quantities are those in the grout, not the rock host. Stress and motion predictions and calculational modeling, however, deal with the free-field quantities in the rock. This is the gage inclusion problem. The historical approach to minimizing the problem was to match the mechanical impedances - the density times the compressive wave speed - of the grout and host. This is the elastic wave, or acoustic, approach. For shock waves, one matches the density times the shock speed. Over the stress level where the materials yield, it was not clear what quantities to match to minimize inclusion effects. We will discuss calculational and experimental work that address this problem.

A major constraint in the inclusion work is that one rarely has a measure of the actual free-field stress or motion in the rock to compare with either the measurements in the grouted holes or with calculations. A number of approaches can be used to, at least, bound the problem. One can use installation geometries which analyses suggest the stress or motion in the grout will approach that in the free-field. For example, one can field a gage in a slot cut in the rock. As the width to thickness ratio of the slot increases, the slot approaches the one-dimensional case where a few reverberations will bring the stress in the grout and gage package to equilibrium with that in the host. Also, the host, grout, and gage package can be modeled analytically and computer calculations performed. This is a very viable approach for one can vary the individual parameters and see their effects. The pitfall of the approach is that while the calculations may be accurate, the modeling of the material response may not have captured phenomena that are important at the stress level, or strain rate, of interest. For some phenomena large scale tests are needed to confirm the modeling of that response. 
A necessary assumption of this work is that gage measurements are sufficiently repeatable for the inclusion studies to be meaningful. This is the precision issue - the scatter about the mean of the numerous repeated, or similar, measurements.

In the experimental work we have attempted to bound the problem, to provide data for comparison with calculations, and to explore techniques that minimize the inclusion problem. With measurements and calculational work to date, we have made progress on the inclusion problem but not solved it.

In the following sections we review the calculational work and then discuss related measurements made on recent nuclear and high-explosive events.

\section{CALCULATIONS}

Calculational work on the gage inclusion problem has been performed at Pacifica Technology ${ }^{1}$ and SRI International; the Defence Nuclear Agency has been the principal sponsor of that work. We have worked closely with the Pacifica Technology group and have fielded inclusion experiments in conjunction with their modeling work. SRII has calculated inclusion effects and performed numerous, small scale experiments. Nagy and Florence (1986) shows their experimental tools and techniques.

Prior to the calculational work, Bass and Cook at Sandia had developed a stress gage package for use in long radial holes on nuclear events. It consists of a $10 \mathrm{~cm}$ ( 4 inch) diameter epoxy cylinder that encapsulated radial and hoop stress sensors and a radial accelerometer. The package was grouted with HPNS2 which shows an approximate, acoustic impedance match with the tuff. The epoxy is a mass castable, aluminum loaded material called REN 3269-1, which is currently distributed by CIBA-GEIGY of East Lansing, MI. The epoxy ${ }^{2}$ shows an approximate acoustic impedance match to the host rock. As interest developed in inclusion work, this gage configuration was questioned. Although there is an approximate impedance match between host, gage package, and grout, there is a significant difference between the compressibilities and yield strengths of the three materials. Smith (1989) shows a sketch of this gage package.

At ranges where the predicted stress was a kilobar or less we fielded paddle gages in transversely oriented holes where the stress wave is incident "side-on" to the hole and paddle. We also initiated a program of high-explosive experiments; in these the risetimes were notably shorter than on the nuclear events. The calculational work addressed both radial and transverse gage configurations.

Swan and Patch (1986) modeled the radially installed, epoxy package coupled to the drill hole in

1. Now a division of Science Applications International Corporation, San Diego, CA

2. Bill Olsson of Sandia measured mechanical properties of this material (Olsson and Jones 1985). 
tuff with the compressible HPNS2 grout. This installation geometry is shown in figure 7.

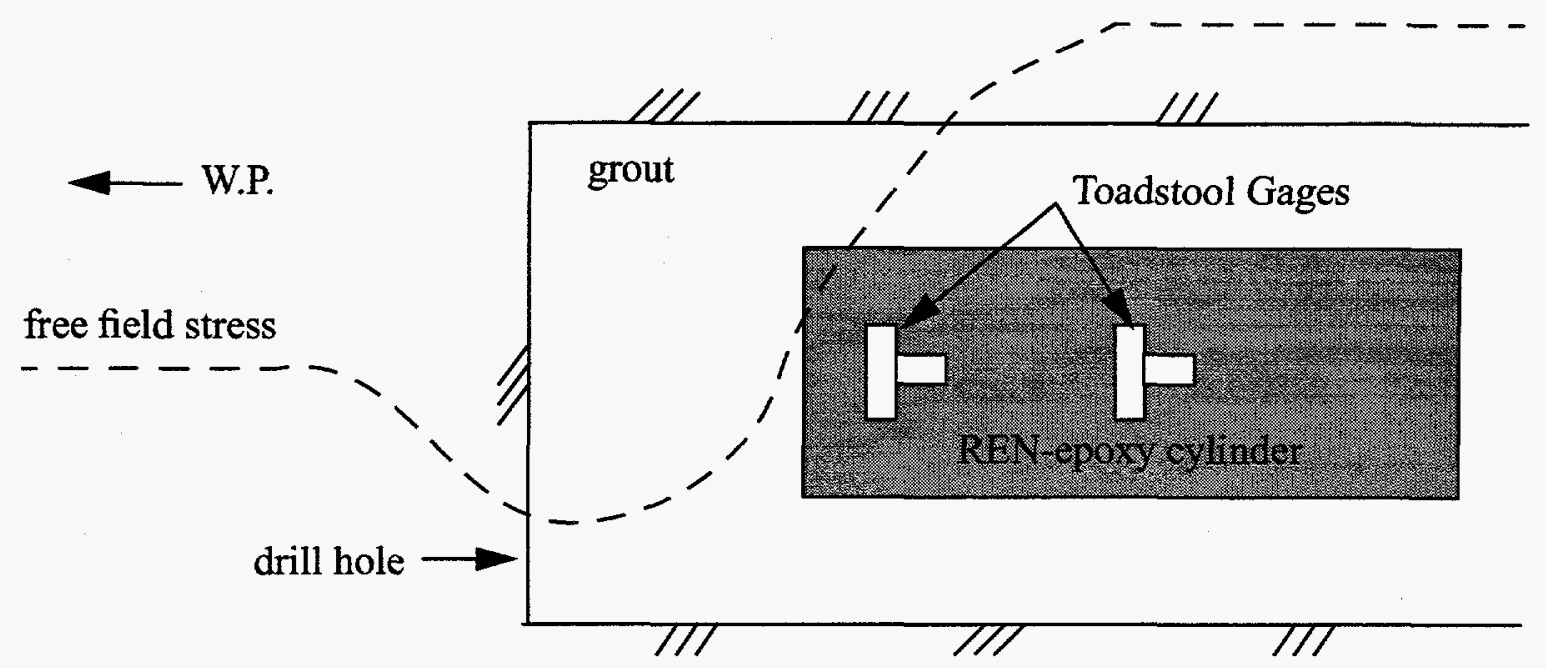

Figure 7. Radially Installed Epoxy Package and Static Stress Distribution

A quasi-static approach was used since the risetime of the nuclear stress wave was long compared to the time to traverse the gage package. The modeling showed that stress in the epoxy package could be three times the free-field stress, varied along the length of the cylinder, and was a strong function of the contrast between the constitutive behavior of the host medium, the grout, and the REN epoxy. The dashed line in the figure is an approximation of the calculated static stress.

Swan and Smith (1987) describes dynamic calculation on the above problem at two location in the epoxy package. A one-dimensional, free-field calculation was used to drive a two-dimension, island calculation which modeled the gage, grout, and host. On the HALFTON experiment we fielded a gage package with sensors located at the two locations. The measured waveform from the front sensor showed a peak of 0.85 kilobar while the calculated stress at that location in the epoxy was 0.78 kilobars. The predicted, one-dimension, free-field stress was 0.55 kilobars. At the center location we measured a peak of 0.95 kilobars compared to a calculated value in the epoxy of 0.94 and a calculated free-field value of 0.3 kilobars. Risetimes were similar; however, the measured unloading of the wave was slower that calculated. In a subsequent calculation, Swan allowed slippage between the grout and the epoxy but this shortened the pulse rather than lengthening it. He suspected that the discrepancy was related to the model for the tuff.

Thus we saw surprisingly good agreement between a calculation and the field experiment. The agreement, however, may be fortuitous, for we did not have a measure of the free-field stress to validate the calculated free-field stress. The latter was the "driver" for the inclusion calculation.

In the same paper Swan discussed calculations on two more configurations. The first is the drill hole loaded side-on, i.e., the transverse hole-paddle gage configuration. The quasi-static calculation of the circular hole showed that the stress amplitude in the grout was 5 to $6 \%$ greater than the free-field stress. Another calculation used a tuff model with one percent less air void and $50 \%$ less strength than used in the first calculation. It showed zero to $1.4 \%$ greater stress inside the grout than in the free-field. The parameters for the host tuff came from two different suites of 
material properties. The next calculation was the dynamic version of the side-loaded hole. It was modeled in plane strain; again, a two-dimensional island was driven by a one-dimensional, spherically symmetric free-field calculation. The results showed that the peak stress in the inclusion was $7.5 \%$ greater than the free-field stress.

Finally the slot geometry was modeled with calculations. Figure 8 shows top and end views of the drill hole, the slot at its end, and the installed gage package. A quasi-static calculation showed

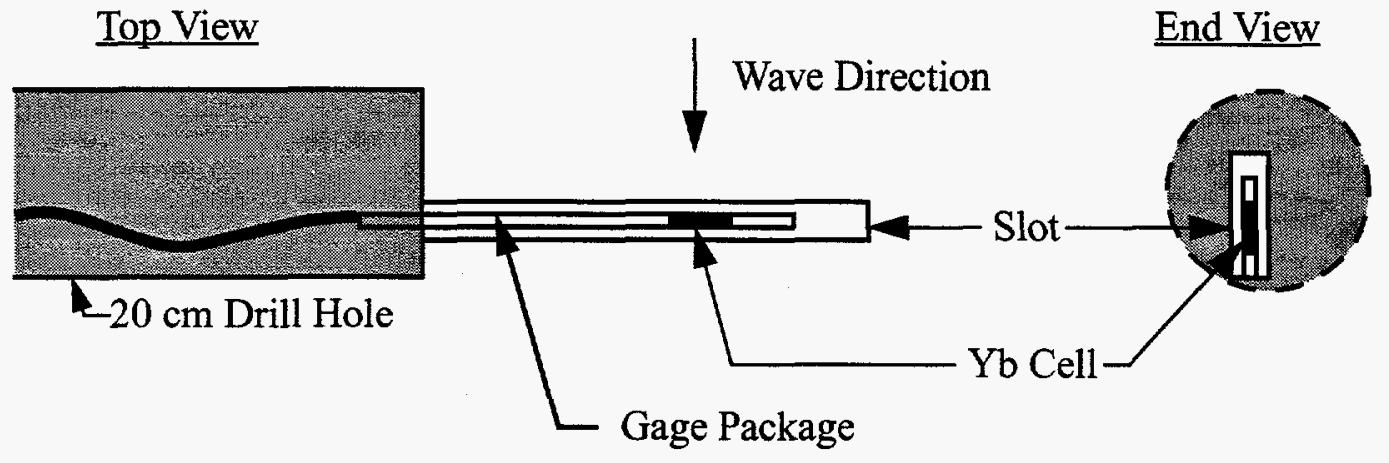

Figure 8. Two Views of the Slot Installation

less than $1 \%$ differences between the two stresses. The dynamic version showed the stress through the central portion to be virtually equal to the free-field. As one approaches the edges of the slot, the far end of the slot, and the transition to the hole from which the slot was cut, there are significant stress concentrations. The magnitude of these and their signs are related to the relative stiffnesses of the grout and rock.

Swan concluded with three observations: 1) stress sensors in slots should be located away from the edges and ends of the slot, 2) measurements from the slot configuration should be closer to the free-field than those from gages in tangential drill holes, and 3) the pressure-volume behavior is the important mechanical property to match between the host rock and grout. That is, the grout needs to compress like the host, or show the same bulk modulus, in order to have the stress in the inclusion approach that in the rock.

\section{MISTY ECHO}

We were interested in the inclusion effects associated with the traditional cylindrical epoxy gage package installed in radially oriented holes with the weak HPNS2 grout. Data from that installation technique were to be compared with those from the gage configurations that the above calculations suggested should approach the free-field stress. For the latter we fielded paddle gages in a series of transversely oriented holes and grouted the holes with a recently developed grout whose compressibility is similar to the host rock. The grout is named GSHSG and was developed by Waterways Experiment Station.

At the quarter kilobar level on MISTY ECHO we installed a Toadstool gage in a 20 centimeter ( 8 inch) diameter, transverse hole. This was the aluminum body and sensor only; that is, without 
the epoxy cylinder and grouted the hole with the matching GSHSG grout. In a nearby radial hole we fielded the traditional Toadstool gage; that is, the aluminum body encapsulated in the epoxy cylinder. HPNS2 was used to couple the package to the host rock. The recorded waveshapes were similar until the stress had unloaded to about one half the peak value. At that time one gage failed. The amplitudes, however, were notably different. The 0.25 kilobar peak from the radially installed gage was $64 \%$ of the 0.39 kilobar peak shown by the transversely installed gage.

These results are the opposite of what the above described calculations predict. They suggest that the radial configuration should "overregister" the free-field by $40 \%$, that is, show 1.4 times the amplitude of the free-field. For the transverse installation with the matching grout the overregistration was calculated to be zero to $10 \%$. Based on subsequent measurements, we believe the transverse calculation more accurately models the field configuration and suspect that the radial configuration is "underregistering", that is, measuring amplitudes below the free-field.

At the nominal half-kilobar level we fielded gage packages in two radial holes and in two transverse configurations. In the radial holes we again fielded Toadstool gages in the REN cylinders and grouted with the weak HPNS2. The transverse array consisted of four, 10 centimeter ( 4 inch) diameter holes and two slots ${ }^{1}$ cut at the ends of 20 centimeter $(8 \mathrm{inch})$ diameter holes. Two of the 10 centimeter holes were to be grouted with the matching GSHSG grout. The third hole contained the SEA CALIP gage described earlier. We planned to grout the fourth hole with HPNS2; the intent was to obtain data to bound the effect of this weaker material. Unfortunately, geologic inhomogeneities compromised the array. In flushing the "cuttings" out of one of the slots, it collapsed at a natural fracture; we located that gage in the 20 centimeter diameter, access hole and grouted it with HPNS2. The next compromise was that the second GSHSG hole was partially grouted when grout leaked through a natural fracture from an adjacent hole; the gage produced a spurious waveform. Thus, the designed, multiple measurements per configuration was compromised to the traverse array shown in the adjacent table.

\section{Gage Emplacement Grout Peak (kilobar)}

$\begin{array}{llll}3136 & \text { slot } & \text { HLNCC } & 0.67 \\ 3143 & 20 \mathrm{~cm} \text { hole } & \text { HPNS2 } & 0.63 \\ 3137 & 10 \mathrm{~cm} \text { hole } & \text { GSHSG } & 0.60 \\ 3144 & 10 \mathrm{~cm} \text { hole } & \text { HPNS2 } & 0.54\end{array}$

Figure 9 shows the waveforms from these gages. At 250 milliseconds ground shock reaches the recording system and "shakes" it for 25 milliseconds. The waveshapes are similar; the amplitudes show some variation. The average and variation of the peak amplitudes is $0.61 \mathrm{kbar} \pm 10 \%$. With only one measurement of stress per configurations we have no measure of experimental error. The differences may be due to this error, emplacement differences, or both. On the other hand the shapes are virtually identical and the peaks are within $\pm 10 \%$ as noted above.

Although emplacement differences offer no ready explanation for the peak variations, the paddle

1. These slots were 1.5 centimeter wide, 12.7 centimeters high, and about 60 centimeters long. They were cut with a chainsaw-like tool. 


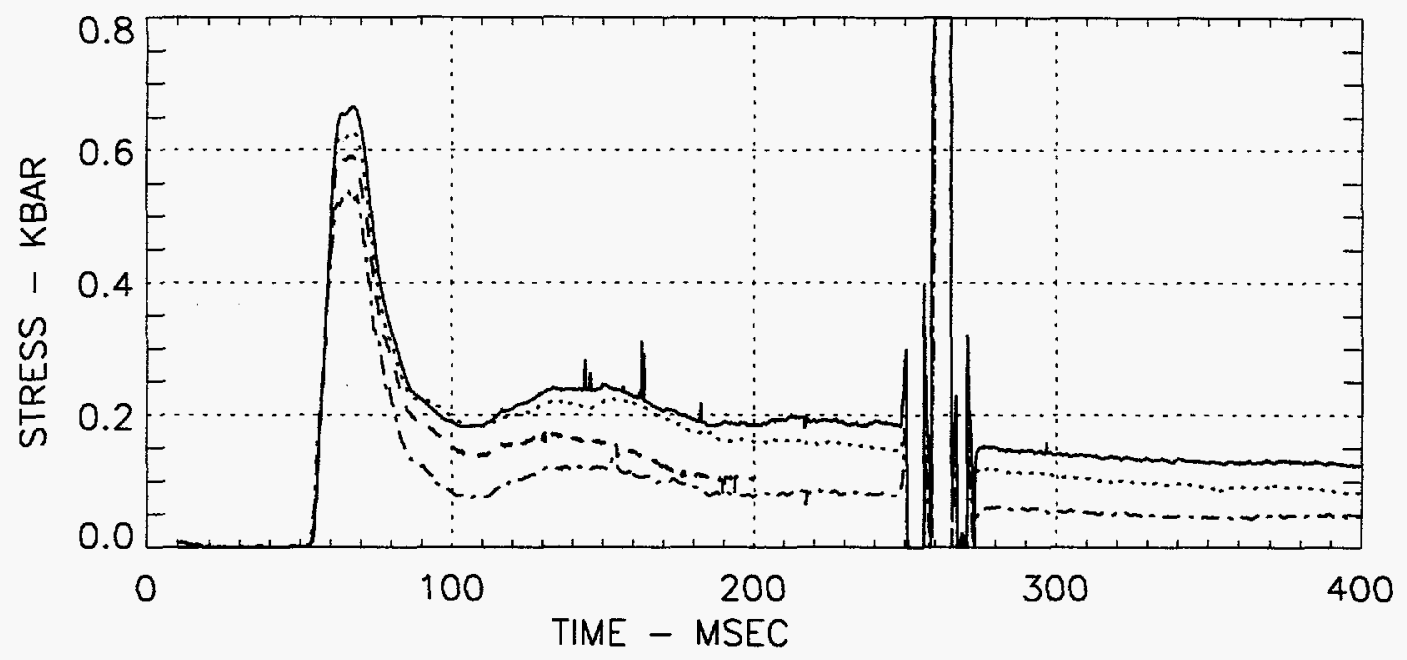

Figure 9. Waveforms from Paddle Gages - MISTY ECHO

traces may be compared with Swan's calculations. The latter show that gages grouted with the weak HPNS2 should have shown $60 \%$ of the free-field stress. This is related to the compressibility of this grout relative to the host rock. We see, however, that the HPNS2 peaks are 0.54 and 0.63 kilobars. We suspect that the culprit is that the material model, used in the calculation for the HPNS2, is incorrect. It had been developed from quasi-static laboratory tests. Under 40 millisecond loading conditions the grout may be notably stiffer, i.e., a strain rate effect. The group of traces may also be compared to the traces from one of the radial, REN-packaged Toadstool gages. Again the waveshapes are similar; however, the 0.42 kilobar peak of the Toadstool gage is $69 \%$ of the average of the transverse paddles. The second radial gage produced a trace that showed a peak of 0.19 kilobars. We discredited this trace and attribute it to a sensor problem, a grouting problem, or geologic inhomogeneities close to the gage package.

Although solid conclusions are difficult to draw from these measurements, some inferences can be made. Based on the earlier discussed calculational work, we estimate that the transverse gages are within $\pm 10 \%$ of the incident free-field stress. In comparison, the data from the radially installed gages at the quarter and half-kilobar level in this tuff suggest that they are underregistering; specifically, they are showing 60 to $70 \%$ of the estimated free-field stress.

\section{DISKO ELM}

On this event we fielded gage inclusion experiments at the 2 and 3 kilobar levels. We wished to see if there were differences, attributable to inclusion effects, between transverse hole and slot emplacements at these stress levels. At each location paddle gages were installed in slots cut at the ends of 20 centimeter ( 8 inch) diameter holes. Similar paddles were located in the access holes. Thus, in both configurations, the gages were loaded "side-on." Figure 10 shows the four obtained waveforms. The lack of fine detail simply reflects low pass filtering of the data prior to digitization. The records terminate shortly after the stress peaks. The electrical leads to the grids were shorted by the compressing action of the stress wave; this is the paddle construction error 
described earlier. As one can see, the differences between the waveforms are small and can readily be attributed to experimental variation rather than the slot versus hole configuration. The traces with the 1.8 kilobar peaks show what looks like a yield phenomena in their rising portions. The similarity of the two traces strongly suggests the yield is in the rock and not the grout. (There was about 9 centimeters of grout in front of, and behind, the paddle in the hole and less than a centimeter of grout on either side of the paddle in the slot.) The similarity of these waveforms suggests that there is no difference, attributable to inclusion effects, between gages in circular holes and slots, and loaded side on, at these stress levels. Further, if one invokes Colby's calculations that suggest negligible inclusion effects for the slot configuration, then one can conclude that tangentially oriented measurements, at this level, are probably close to the radial, free-field stress.

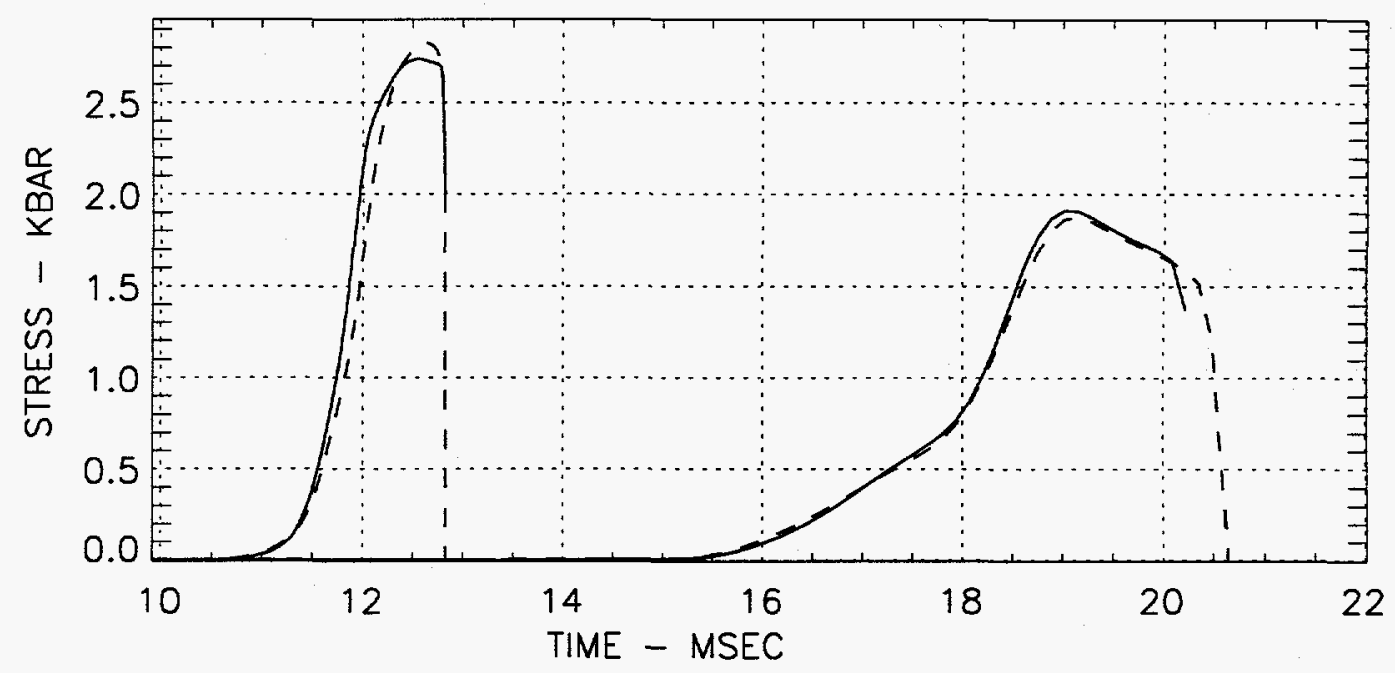

Figure 10. Waveforms from Slot Installations (Solid Traces) and Hole Installations (Dashed Traces) - DISKO ELM

Reproducibility of stress traces had been seen earlier. On a $907-\mathrm{kg}$ ( 2000 pound) high-explosive experiment called ONETON we fielded gage paddles with dual ytterbium grids (Smith 1994). Spacing between the grids was about 30 centimeters. Four pairs of traces showed similar waveshapes and peaks within $5 \%$ of each other. The fifth pair showed peaks within $7 \%$.

\section{MINERAL QUARRY}

Two inclusion experiments were fielded on this event. They addressed the radial versus transverse installation configurations. At the $1.5 \mathrm{kilobar}$ level, four transverse paddles were fielded; two in slots and two in 10 centimeter diameter holes. The holes were grouted with the matching GSHSG grout. For the paddles in the slots we used a low viscosity grout called HLNCC to ensure that the annulus around the paddle was filled. In the long, radially oriented, IH1 hole we fielded an epoxy cylindrical gage at the same range as the transverse paddles. Hole IH1 was grouted with HPNS2. There was a mapped fault 18 meters in front of these gages. We suspect that differential motion occurred on the fault; this action distorted the peak detail and reduced the peak amplitude. Figure 11 shows the traces. Most were terminated by motions on another fault located behind the gages; the exception lasted until 54 milliseconds. The low amplitude trace was measured by the gage 


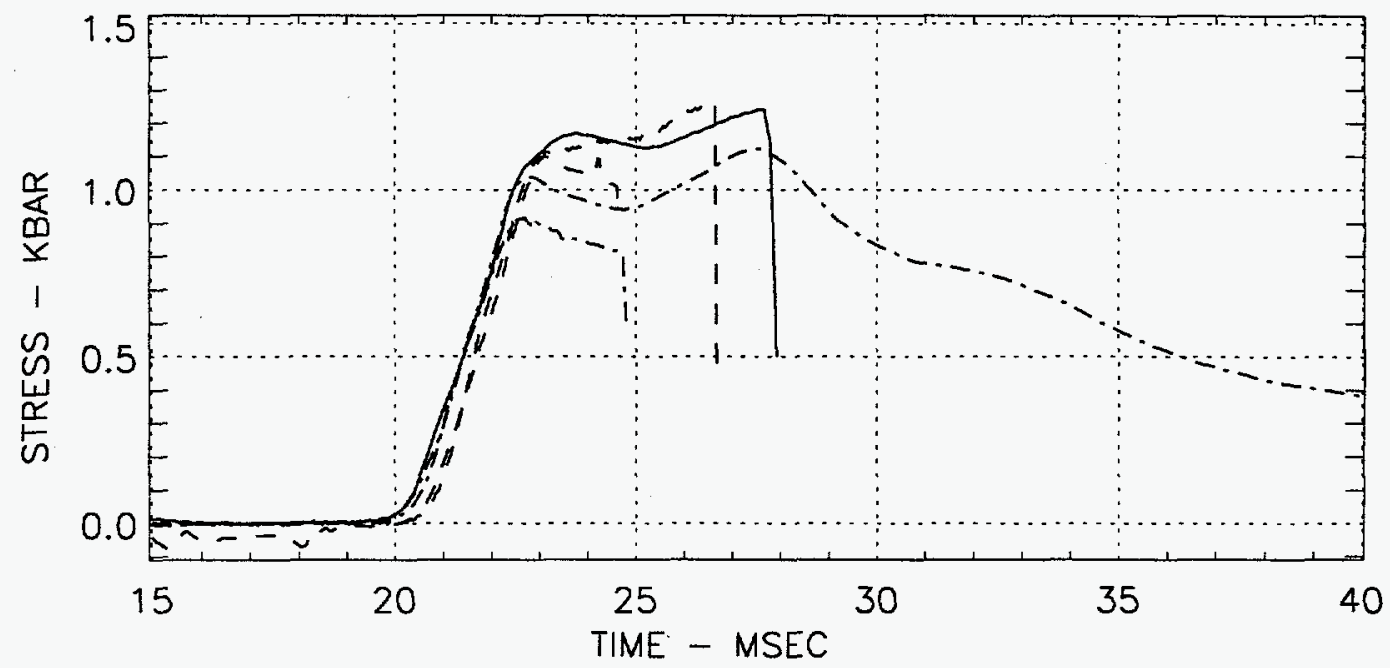

Figure 11. Waveforms from a Radially Installed Gage (Solid Trace) and Transversely Installed Gages (Other Traces) - MINERAL QUARRY

package in the $\mathrm{IH} 3$ slot. According to field notes made at the time of grouting, we suspected that air bubbles were entrained in the grout ${ }^{1}$. The low amplitude trace may be the response of gage with a nearby air bubble. In any case, we eliminate this trace from the comparison. The solid trace was measured by the radially installed gage. The first peaks of the waveforms vary from 1.04 to 1.17 kilobars; the 1.17 value was produced by the epoxy-packaged gage in the radial hole. The fault altering of the waveforms clouds the comparison, but we tentatively claim a $10 \%$ variation between peaks from a cylindrical gage in a radial hole, paddle gages in transverse slots, and paddle gages in transverse holes at this 1.5 kilobar stress level. (Clearly, we are not dealing with readily repeatable, laboratory-type measurements.)

At the 0.2 kilobar level on MINERAL QUARRY we fielded ytterbium paddles in the transverse holes IH7 and 8 and grouted them with the GSHSG material. In the long radial hole IH9 we again installed an epoxy cylinder package at the same range as the two paddles. Again the weak HPNS2 grout was used ${ }^{2}$. The two paddles produced peak stresses of 0.18 and 0.2 kilobars. The radial gage gave a value of 0.14 kilobars. Like MISTY ECHO, the low value for the radially installed gages suggests that there is an inclusion problem with this configuration at low stresses.

Waveforms from this event confirm our earlier hypothesis. At higher stresses in this tuff there is not a significant inclusion problem with the radial or transverse gage configuration. At lower stresses the cylindrical package in radial holes underregisters the free-field stress and the transverse paddles appear to register correctly. Measurements on MINERAL QUARRY suggest that one kilobar is roughly the dividing stress for these two regimes. (We suspect the tuff is yielding about this level.)

1. This happens readily. A grout hose can slip off the pump, the grout hopper can empty, or the grout pump can plug and has to be disassembled.

2. Field bosses are reluctant to let us use the GSHSG in long radial holes. The concern is that the grout pump may become plugged by this relatively viscous grout and one may, by default, obtain a partially open, long radial hole. The latter would be a containment concern. 


\section{DISTANT ZENITH}

On this event we fielded a paddle in the transverse hole IH8 at the 1.5 kilobar level and filled the hole with the matching grout. The paddle incorporated two ytterbium grids. They were separated by 30 centimeters. We were interested in the reproducibility of stress traces. Geologic mapping of the tunnel preshot showed a fault zone in front of this hole. Figure 12 shows the traces from the

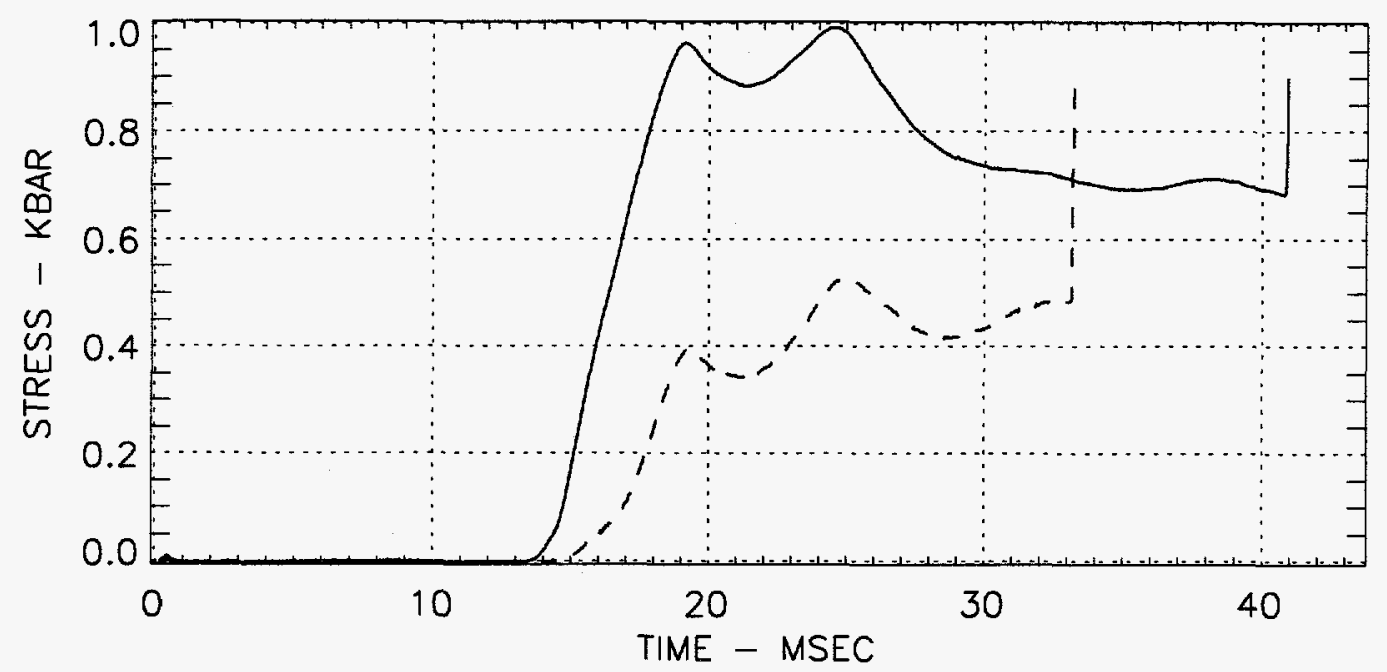

Figure 12. Waveforms from Adjacent Gages-DISTANT ZENITH

two grids. We see amplitudes that differ by a factor of two and somewhat different waveshapes. Also note that the lower trace leaves the baseline about a millisecond after the other trace. The nominal explanation is that a fault in front of the gage package was discontinuously open and the sensors saw different transmitted stresses. Other gage measurements behind the fault showed notably reduced stresses, thus we do not attributable the lower trace to a sensor, or grouting, problem. Once again we learned that geological inhomogeneities can raise havoc with gage measurements.

\section{HUNTERS TROPHY}

A series of measurements on this event are of interest to inclusion and reproducibility studies. At three ranges we fielded duplicate gages. Figure 13 shows the radial stress measured in the transverse $\mathrm{IH} 4$ and 5 holes. We see about a 10\% difference in amplitudes and similar shapes. These gages were separated 1.6 meters vertically. Similar duplicate measurements at greater ranges show greater differences in peak stresses but we attribute these differences to geologic effects. (In this area drill holes were changing shape and size over a few days.) Accelerations in the outer holes, however, were similar; see figure 14.

At a closer range we fielded epoxy cylinder, gage packages in the radial $\mathrm{IH} 2$ hole. The spacing between the two packages was 7.0 meters. The two stress traces are shown in figure 15. The gaps 


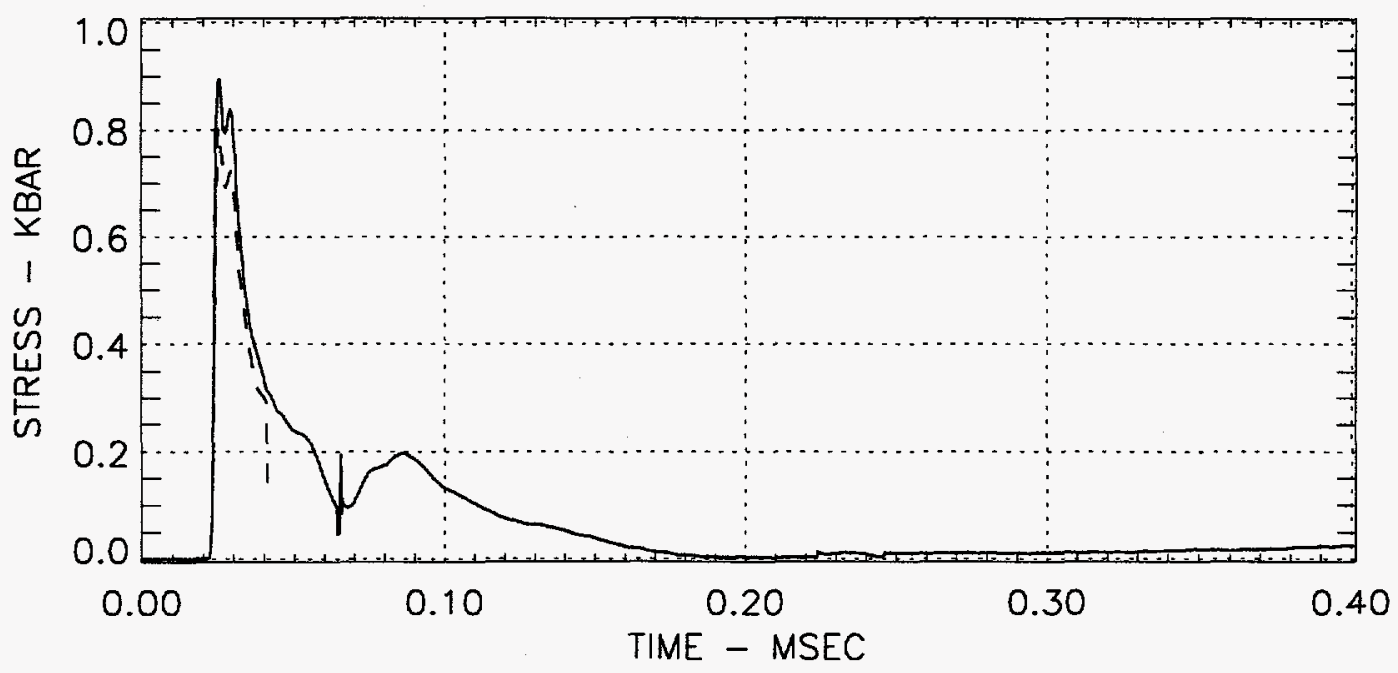

Figure 13. Waveforms from IH4 and IH5 Gages - HUNTERS TROPHY

in the traces occurred when the electrical leads were momentarily shorted. Of interest is the spike at the front of the close-in waveform. We suspect that the spike is a result of the impedance mismatch between the weak HPNS2 grout and the strong epoxy cylinder. Wave reflection off the rear of the epoxy cylinder quickly brings the stress to equilibrium with the host grout. For the outer gage the risetime is too slow to see this effect.

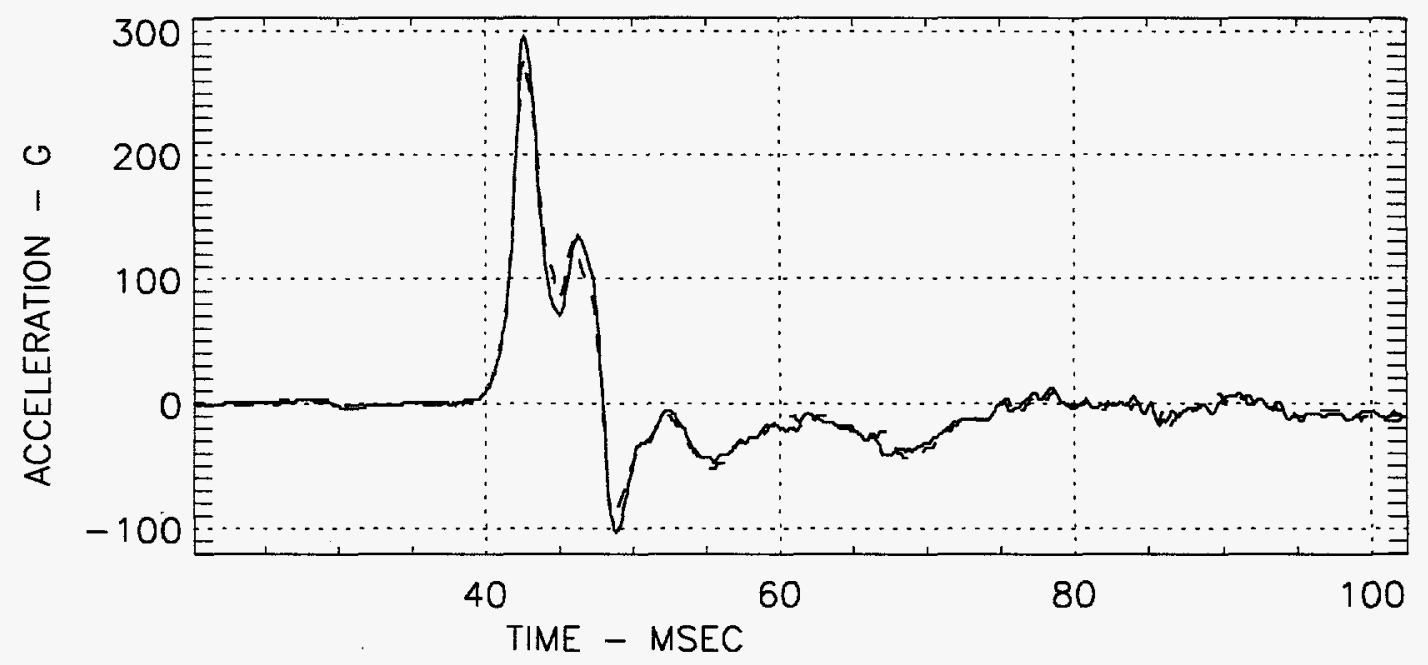

Figure 14. Waveforms from Accelerometers - HUNTERS TROPHY 


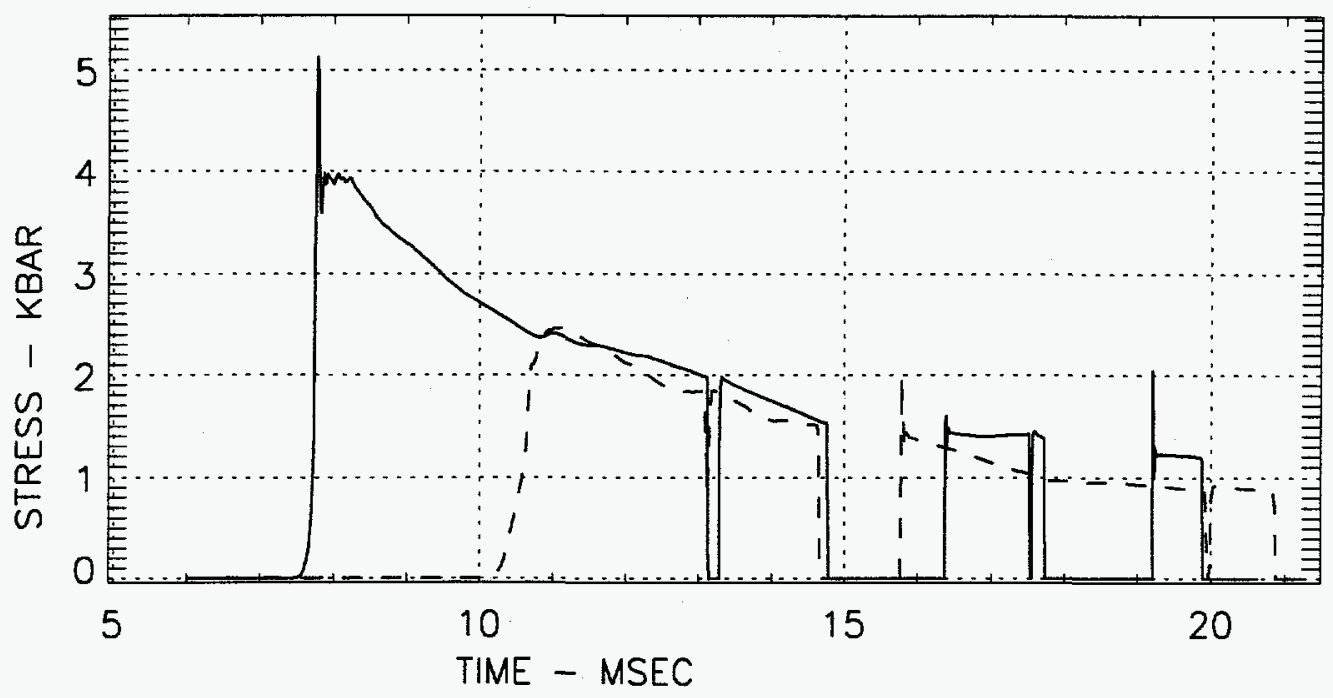

Figure 15. Waveforms from Radially Installed Gages - HUNTERS TROPHY

High-Explosive Tests

Over the past 15 years we have conducted a series of high-explosive (HE) tests with various objectives: containment phenomenology, dynamic material properties, gage development, and LOS flow. The following sections describes data from those tests that addressed gage inclusion effects.

\section{BLOCKSHOT}

We mentioned earlier we rarely have a measure of the real free-field stress in field experiments. This is true when one drills holes in rock and installs gages. If, however, one casts a block of grout containing gages, one can approach the free-field condition. In this case a few reverberations within the one centimeter thick paddle gage will bring the package to stress equilibrium with the host. The scale of gage testing experiments needs to be close enough to the full scale experiment that similar phenomena are acting. Also, one needs grout material behind the gage package to measure the unloading wave. Thus the size of the HE charge and grout block to simulate full scale effects is a compromise between adequate simulation and available dollars.

Nagy and Florence (1986) performed laboratory scale inclusion experiments in which miniature gages were cast in a 30 centimeter grout sphere and loaded with a 3/8 gram explosive source. The data were compared to those from gages located in holes cast in the sphere and coupled to the host with the same grout. At the one to two kilobar level the gages installed in the holes produced peaks that were 1.5 times the peaks from the cast-in gages. The SRII experimenters suggested that slippage at the interface between the host and the grout in the hole lead to the greater stress.

The thrust of the BLOCKSHOT experiment was to explore the SRII results at a larger scale. Additionally, we altered the boundary condition at the edge of the hole to explore the slippage 
hypothesis. This boundary consisted of splined holes with one centimeter "teeth" on the circumference of the 10 centimeter diameter holes. Another variable was to grout some gages in the cast-in holes with a grout that was stronger than the host. The host was a standard, acoustic matching grout, called DSRM2. The strong grout was HSG which shows a strength of ten times the DSRM2. Gages were located 1.2 meters from a 45 kilogram sphere of nitromethane explosive. Three gages were cast in the block. Two each of the other configurations were installed a few hours after the main block had been cast. One gage produced a noise trace; ten others produced viable and similarly shaped traces. Of these, one showed a peak of 1.75 kilobars; the average and variation of the other nine was $2.27 \pm 8 \%$ kilobars. Most gages showed a series of similar oscillations. We suspect that the grout near the gages was crushing in a "stick-slip" fashion. The exceptions were the gages grouted with the strong grout which showed none of the oscillations seen on the other gages. We suspect that the HSG was not crushing at this stress level. Otherwise peaks, waveshapes, and impulse were quite similar between the various configurations.

Our interpretation of the above work is that the stress level was just above the yield range of the grout host; the grouts yielded and came to equilibrium with the host. At stress in and below the yield range, however, one may encounter under or overregistration. Also, grouted holes in a grout block may not be a valid simulation of grouted holes in a host rock. We will see enigmatic results in the next two experiments.

Summarizing the BLOCKSHOT experiment we can say that, at the two kilobar level, gages loaded by 45 kilogram of $\mathrm{HE}$ in a grout host show no difference between those cast in the grout block and those emplaced in holes and coupled to the host with the same grout. There appears to be no inclusion effect in this configuration and stress level. More details on the experiment are given in Smith (1989). An extensive discussion of material response models developed using the dynamic BLOCKSHOT data is given in Fogel (1989).

\section{HALFTON}

This event consisted of 453 kilograms of TNT fired in a partially saturated tunnel bed tuff (Smith, 1995). Two gages were fielded at the same range; one was installed in a slot and a similar one was installed in a 10 centimeter diameter hole. Figure 16 shows the two obtained waveforms. The 0.26 kilobar peak from the gage in the slot is $66 \%$ of the 0.39 kilobar peak generated by the gage in the hole. Calculations showed (Swan and Smith 1987) that the peaks should be within 5\% of each other. In the one millisecond risetime there were numerous transits across the hole diameter; thus the grout, and gage, should have achieved stress equilibrium with the host. Note also that in the residual phase -7 milliseconds and beyond - the amplitude shown by the gage in the hole is notably larger than that shown by the gage in the slot. Thus we see unexplained peak amplitude and shape differences. Both the hole and slot were examined later with mineback and showed nothing, air gaps, for example, that would explain the difference between the two installations. Our sense here is that the waveforms reflect a difference in the dynamic yielding of the grouted hole versus the slot. More specifically, it may be the lack of material yielding that leads to these results. 


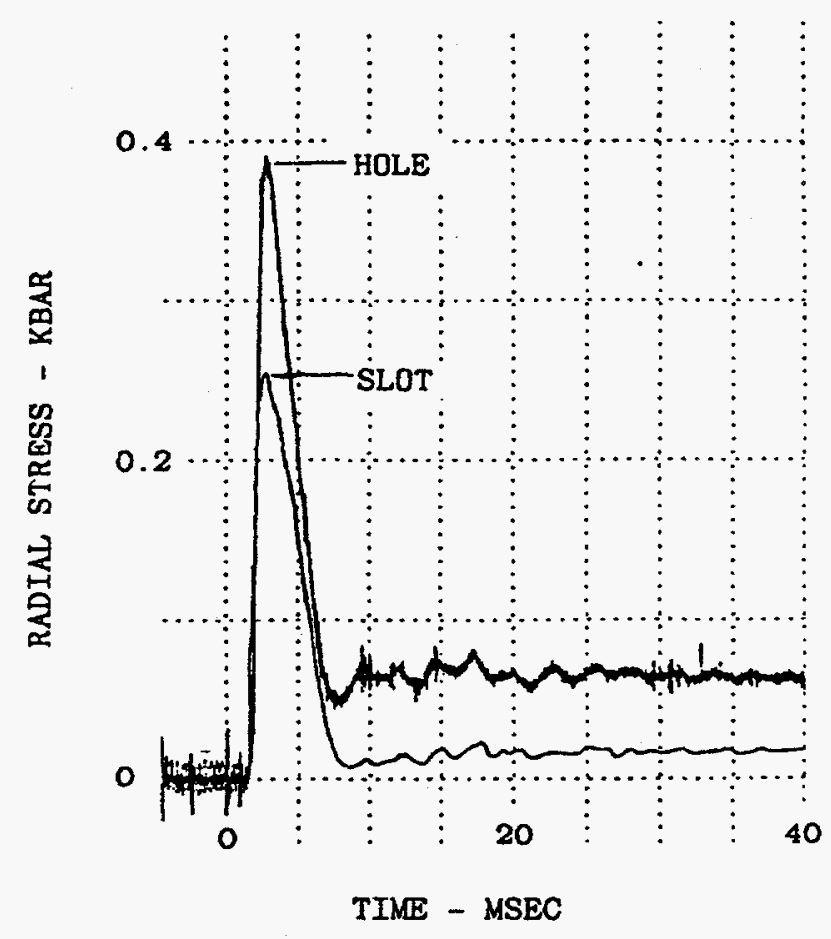

Figure 16. Waveforms from Paddle Gages - HALFTON

\section{DYNAMIC GROUT II}

Like the previously described event, this was another 453 kilogram TNT event in G Tunnel; however, at the location of this event the tuff was nearly saturated. Again, we added a gage in a hole and one in a slot. Both were located 3.3 meters from the center of the TNT source. The matching GSHSG grout was used in the hole; the low viscosity HLNCC was used in the slot. Figure 17

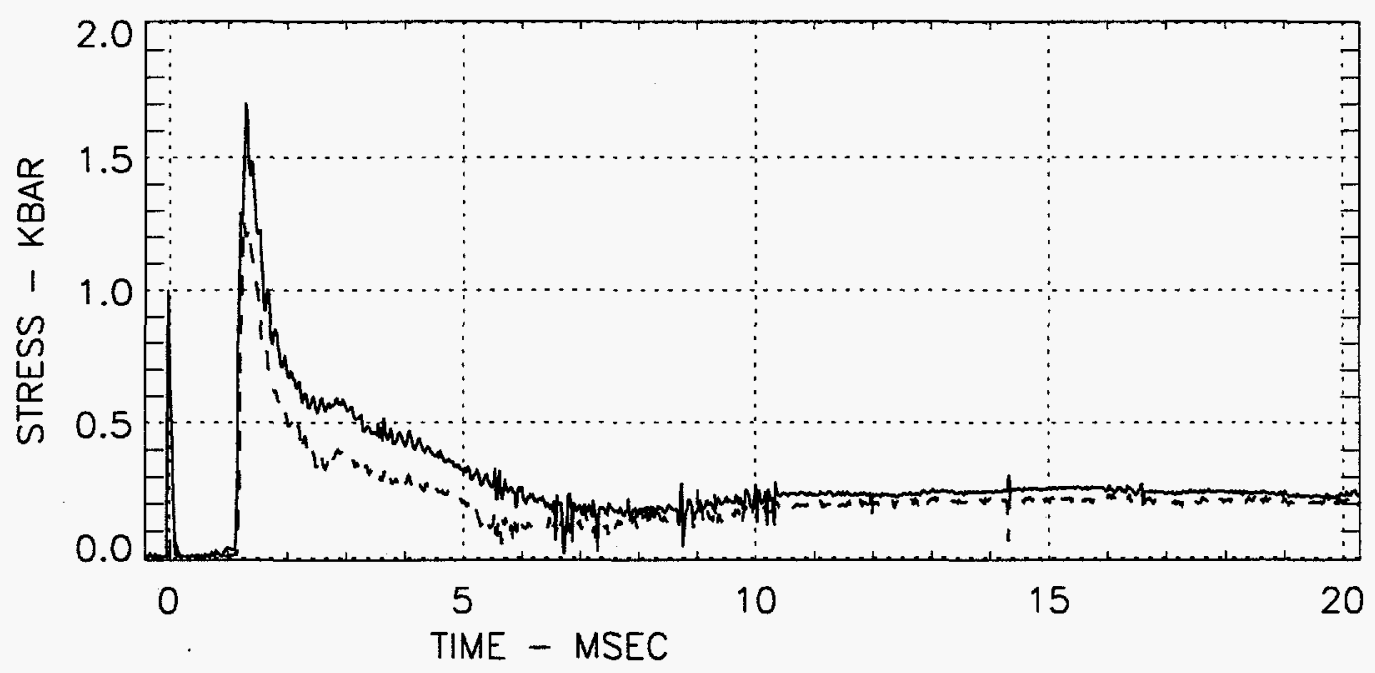

Figure 17. Waveforms from Paddle Gages-DGSII 
shows 20 milliseconds of the waveforms. The 1.25 kilobar peak from the gage in the slot is $74 \%$ of the 1.7 kilobar peak produced by the gage in the hole. The ordering of the peaks is consistent with the HALFTON results. In this experiment the waveshapes are similar. At this higher stress level than in the previous comparison, the tuff may be yielding more and allowing the stresses, after the peaks, to approach each other.Again, our only suggestion about the peak difference is that of a difference on dynamic yielding of the two configurations.

\section{PRE-MILLYARD 8}

PRE-MILLYARD 8 was a 1814 kilogram nitromethane surface event fired in recompacted Yuma dirt. It was a precursor to the MILLYARD nuclear event. We fielded two REN cylinder gages and two paddles at the 2.4 meter range. We wished to assess the differences in response between these two gage packages in this very compressible material prior to choosing gages for the nuclear event. Figure 18 shows the waveforms from the four gages. The paddle gages (lower traces) show a rise to 0.6 kilobars in 40 to 50 microseconds and then gradually unload. With a transit time through the paddle of about 5 microseconds, there are 8 to 10 transits through the package during the risetime. The paddle with the thin electrical shield broke at 9 milliseconds. The bare paddle shows that the 50 bar stress level seen on both paddles in the 7 to 9 millisecond timeframe decays to near zero stress by about 15 milliseconds. These are credible records. They are consistent with other half kilobar records and with calculated waveforms.

The REN encapsulated gages produced notably different records. The large first peak (1.2 kilobars) is probably the result of the impedance mismatch between the dirt and the REN. This is the phenomena we noted in the HUNTER TROPHY close-in record. We suspect the unloading to near zero stress at 3.2 milliseconds is a result of a tensile wave - a reflection from the far end of the cylinder. The calculated round trip time in the cylinder supports this interpretation. A second peak is followed by an unloading to negative amplitude. The latter persists to the end of the recording. This response is similar to that described by Swan and Patch (1986) in their description of the calculated results of the REN cylinder surrounded by a soft grout in a drill hole that is loaded end on.

The PRE-MILLYARD 8 measurements show that a gage package that is "thick" compared to the risetime of the stress wave and notably stiffer than the host material will produce an electrical trace that is significantly different from the incident waveform.

Some effects from installing and grouting gages in drill holes can be inferred from these "scoping" measurements. Inclusion effects on peak stresses can range from about $60 \%$ underregistration to $200 \%$ overregistration. These can be minimized by choices of gage package materials, grouts, and installation geometries. Inclusion effects appear to diminish as the stress level rises above the yields of the materials. Calculational modeling has been useful in guiding the field measurements, although there are disagreements between the two. Either the modeling of the materials may not have captured important, but subtle phenomena, or various influences may have compromised the field measurements. Geologic inhomogeneities also confound the field measurements. Gage inclusion problems in tuff rock at the kilobar level have not been solved, but, perhaps, have been bounded. 


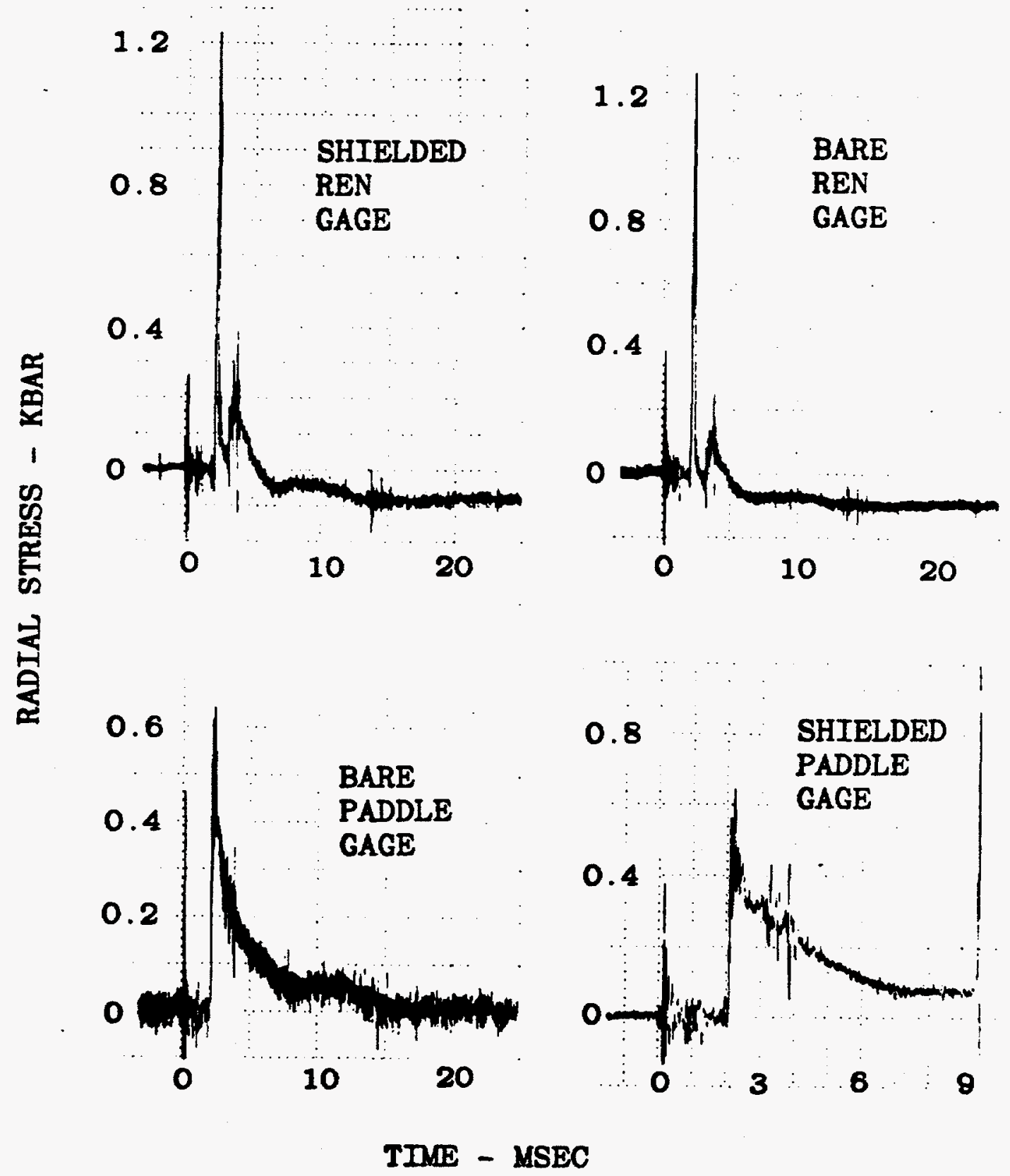

Figure 18. Waveforms from Two Cylinder Gages and Two Paddle Gages - PRE-MILLYARD 8 


\section{Conclusions}

In this document we have described the development of gages and fielding techniques to measure stresses and motions on underground tests. We have concentrated on a gage that measures a close analog of stress in the 0.2 to 20 kilobar amplitude range. Motion measurements were obtained by integrating measured acceleration waveforms.

To examine the stress field that remains after the passage of the dynamic motion we investigated gage and cable survival. Gage packages often survive but non-uniform motions of the host tuff at the one to five kilobar level usually sever gage cables.

Field measurements, guided by calculational simulations, were made to investigate the gage inclusion problem. Work to date suggests that this problem is a minimum when the stress is above the yield strength of the tuff and grout. Below yield levels, measured stress in the grout that couples the gage to the host, can range from 60 to $200 \%$ of the stress in the host. 


\section{References}

DeCarli, P.S., Keough, D. D., and Cooper, T. (1992) Yield Estimation Using Steel Flatpack Gage Measurements, Volume 1-Measurement Description. SRI International, Menlo Park, CA Defense Nuclear Agency, DNA-TR-92-49-V1, Sept. 1992.

Fogel, M. (1989) Dynamic Properties of DSRM-2 Grout, in Proceedings of the Fifth Symposium on Containment of Underground Nuclear Explosions - Volume 1, Sept. 1989, Mission Research Corp. Santa Barbara, CA

Ginsberg, M. J., Grady, D. E., De Carli, P. S., and Rosenberg, J. T. (1973) EFFECTS OF STRESS ON THE ELECTRICAL RESISTANCE OF YTTERBIUM AND CALIBRATION OF YTTERBIUM STRESS TRANSDUCERS. Stanford Research Institute, Menlo Park, CA Defense Nuclear Agency, DNA 3577F, Aug 1973.

Grady, D.E., Smith, C.W., Muller, G.M., Mahrer, K.D., and Peterson, C. F. (1974) IN SITU CONSTITUTIVE RELATIONS OF SOILS AND ROCKS. Stanford Research Institute, Menlo Park, CA Defense Nuclear Agency, DNA 3671Z, March 1794.

Hartenbaum, B. A. (1978) THE DESIGN OF SUBTERRANEAN INSTRUMENTATION CABLES TO SURVIVE LARGE AMPLIDUDE GROUND MOTIONS. H-Tech Laboratories, Inc. Santa Monica, CA Defense Nuclear Agency, DNA 4636F, July 1978.

Keller, C. and Florence, A. (1988) CALIP GAUGE DEVELOPMENT PROGRAM. Science and Engineering Associates, Santa Fe, NM Defense Nuclear Agency, DNA-TR-88-48, February 1988.

Keough, D. D., DeCarli, P. S., Florence, A. L., Mak, R., Walter, D. F., and Rosenberg, J. T. (1986) INVESTIGATION OF THE CREDIBILITY OF IN-SITU MEASUREMENTS OF RADIAL AND TANGENTIAL STRES IN A SALT TEST BED. SRI International, Menlo Park, CA Defense Nuclear Agency, DNA-TR-86-169, May 1986.

Lilley, E. M. and Stephens, D. R. (1971) Electrical Resistance of Ytterbium as a Function of Temperature and Pressure, TID-4500 (UC-4), Lawrence Radiation Laboratory, Livermore, CA 
Morrill, K. B., Davis, H.C., and Hartenbaum, B.A. (1981) TESTS OF SUBTERRANEAN INSTRUMENTATION AND COMMUNICATION CABLE CONDUITS SUBJECTED TO LARGE AMPLITUDE SHEAR OFFSETS. Merritt Cases, Inc., Redlands, CA and H-Tech Laboratories, Inc. Santa Monica, CA Defense Nuclear Agency, DNA 5641F, January 1981.

Nagy, G. and Florence, A. L. (1986) LABORATORY INVESTIGATION OF CONTAINMENT OF UNDERGROUND EXPLOSIONS. SRI International, Menlo Park, CA Defense Nuclear Agency, DNA-TR-86-271, July 1986.

Olsson, W.A. and Jones, A.K. (1985) Mechanical Properties of an Aluminum-Filled Epoxy (SAND85-2133) Sandia National Laboratories, Albuquerque, NM, November 1985.

Smith, C. W., Grady, D. E., Seaman, L. and Peterson, C. F. (1972) CONSTITUTIVE RELATIONS FROM IN SITU LAGRANGIAN MEASUREMENTS OF STRESS AND PARTICLE VELOCITY. Stanford Research Institute, Menlo Park, CA Defense Nuclear Agency, DNA 2883I, January 1972.

Smith, C. W. and Burnside, G. W. (1982) The Ytterbium Fluid-Coupled Gage (SAND82-0409C), in CONFERENCE ON INSTRUMENTATION FOR NUCLEAR WEAPONS EFFECTS, MARCH 30 - APRIL 1, 1982, Volume 1- Proceedings. Kaman Tempo, Alexandria, VA July 1982

Smith, C.W. (1989) Gage Inclusion Experiments, in Proceedings of the Fifth Symposium on Containment of Underground Nuclear Explosions - Volume 1, Sept. 1989, Mission Research Corp. Santa Barbara, CA

Swan, C.C. and Patch, D. F. (1986) EQUILIBRIUM ANALYSIS OF AXIALLY LOADED CYLINDRICAL INCLUSIONS, Pacifica Technology, Del Mar, CA Defense Nuclear Agency, DNA-TR-86-346, May 1986

Swan, C.C. and Smith, C.W., (1987) Theoretical and experimental Analysis of In-Situ Gauge Inclusion Effects, in Proceedings of the Fourth Symposium on Containment of Underground Nuclear Explosions - Volume 1, Sept. 1987, United States Air Force Academy, Colorado Springs, $\mathrm{CO}$

Truilio, J.G. (1991) A Methodology for Validating Gauges. Nuclear Weapons Effects Testing Conference, April 1991, U.S. Army Waterways Experiment Station, Vicksburg, MS 


\section{DISTRIBUTION:}

Dr. N.R. Burkhart,L-221

Lawrence Livermore National Laboratory P.O. Box 808

Livermore, CA 94550

Dr. F.N. App, F659

Los Alamos National Laboratory

P.O. Box 1663

Los Alamos, NM 87543

Dr. W.M. Brunish

Los Alamos National Laboratory

P.O. Box 1663

Los Alamos, NM 87543

FCDNA/FCTT (5 copies)

attn: Dr. B. Ristvet

1680 Texas St.

Kirtland AFB, NM 87117

FCDNA/FCTO

attn: M. O'Brien

1680 Texas St.

Kirtland AFB, NM 87117

Dr. E. Peterson

S-Cubed

P.O. Box 1620

LaJolla, CA 92038

Dr. N. Rimer

S-Cubed

P.O. Box 1620

LaJolla, CA 92038

Dr. D. Patch ( 2 copies)

SAIC/PacTec Division

10260 Campus Point Dr., M/SC2

San Diego, CA 92121
Dr. A. Florence

SRI International

333 Ravenswood Ave.

Menlo Park, CA 94025

Paul DeCarli

SRI International

333 Ravenswood Ave.

Menlo Park, CA 94025

Robert Bass

7705 Cedar Canyon Pl. NE

Albuquerque, NM 87122
MS9018 Central Technical Files, 8523-2

MS0899 Technical Library, 4414 (5)

MS0619 Print Media, 12615

MS0100 Document Processing, 7613-2

for DOE/OSTI (2) 